\title{
Maximizing Function and Quality of Life of Patients with Glioblastoma after Surgical Resection: A Review of Current Literature
}

\author{
Matthew Smith-Cohn'1, Zhijian Chen², David Peereboom³, Glen Stevens ${ }^{3}$ \\ ${ }^{1}$ Department of Neurology, Clinical Neurosciences Center, University of Utah, Salt Lake City, UT, USA \\ ${ }^{2}$ Massey Cancer Center, Virginia Commonwealth University, Richmond, VA, USA \\ ${ }^{3}$ Rose Ella Burkhardt Brain Tumor and Neuro-Oncology Center, Cleveland Clinic, Cleveland, OH, USA \\ Email: matthew.smith-cohn@hsc.utah.edu
}

How to cite this paper: Smith-Cohn, M., Chen, Z.J., Peereboom, D. and Stevens, G. (2016) Maximizing Function and Quality of Life of Patients with Glioblastoma after Surgical Resection: A Review of Current Literature. Journal of Cancer Therapy, 7, 857-888.

http://dx.doi.org/10.4236/jct.2016.712085

Received: May 9, 2016

Accepted: November 1, 2016

Published: November 4, 2016

Copyright $\odot 2016$ by authors and Scientific Research Publishing Inc. This work is licensed under the Creative Commons Attribution International License (CC BY 4.0).

http://creativecommons.org/licenses/by/4.0/

\begin{abstract}
After surgical resection, patients with glioblastoma require many aspects of care to maximize function and quality of life. Patients face a multitude of hurdles that require the expertise of a variety of specialists. Here we will review the current literature on management of glioblastoma patients after surgical resection.
\end{abstract}

\section{Keywords}

Palliative, Glioblastoma, Steroids, Seizure, Rehabilitation, Myopathy

\section{Introduction}

Glioblastomas (GBM), the most common primary brain tumor of adults [1], are known to be among the most devastating of cancers. A multidisciplinary approach is required to maintain patient functionality and quality of life. Glioblastoma patients face a variety of debilitating symptoms including fatigue, cognitive changes, headaches, sleep disturbances, depression, and seizures [2]. This myriad of ailments requires collaboration between neurosurgeons, neuro and medical-oncologists, neuroradiologists, radiation oncologists, rehabilitation specialists, psychologists, psychiatrists, palliative care specialists and others. The aim of this paper is to review the current literature regarding key management topics crucial to the quality of life of these patients after surgical resection.

\section{Current Standard Treatment}

Surgical resection is a common starting point for the treatment of glioblastoma pa- 
tients. An analysis of 28 studies found a median of a 3 month survival advantage with gross total resection when compared to subtotal resection (with a total lifespan of 14 versus 11 months respectively) [3]. Additionally, gross total resection has been shown to improve Karnofsky scores by a mean of 6.8 , where there was no improvement in the scores of the subtotally resected group [4]. The extent of surgical resection is limited by the tumor's infiltration of eloquent areas such as the motor strip. Because of the nature of malignant gliomas to diffusely spread the main tumor mass, surgery will never be curative [5]. Even a hemispherectomy as pioneered by Walter Dandy in 1928 resulted in reoccurrence and did not improve overall survival [6].

After surgery, most patients follow the "Stupp protocol" [7], receiving external-beam radiation for $60 \mathrm{~Gy}$ in 30 fractions 5 days a week concurrent with temozolomide (an alkylating agent) $75 \mathrm{mg} / \mathrm{m}^{2} /$ day orally on days $1-42$. Upon completion of radiation therapy, and after a 28-day break, temozolomide is administered at higher doses of 150 - $200 \mathrm{mg} / \mathrm{m}^{2} /$ day orally on days $1-5$, and every 28 days thereafter [7]-[11]. When progression is found, patients are then typically managed at the discretion of the treatment team which may include a combination of additional surgery, radiotherapy and additional chemotherapies. Overall, this addition of temozolomide to standard radiation therapy afforded a median survival benefit of 2.5 months (14.6 versus 12.1 months), with a progression free survival advantage of 1.9 months (6.9 versus 5.0 months) [7], and was found to increase the overall five year survival rate from $1.9 \%$ to $9.8 \%$ [12].

\section{Neurosurgical Considerations}

GBMs diffusely infiltrate surrounding brain parenchyma, making complete resection difficult or impossible. However, surgical resection can reduce intracranial pressure and reverse loss of neurological function from mass effect of the tumor and related vasogenic edema. Eloquent areas of the brain invaded by tumors, such as Broca's area and the motor strip, pose a neurosurgical challenge. Surgical technologies currently used to minimize damage to these areas include neuromonitoring and awake brain surgery [13], intraoperative corticography and stimulation, navigation-assisted surgery [14] and intraoperative MRI (iMRI) assisted surgery [15]. Tumor-specific fluorophores, such as 5-aminolevulinic acid (5-ALA), are actively being investigated for tumor resection during surgery. Surgical resection with use of both 5-ALA with iMRI has been shown to improve the extent of resection in randomized controlled trials [16] [17]. Use of these modalities increased the progression-free survival but unfortunately has not been shown to increase overall survival [16]. After surgery, patients face edema, intracranial hemorrhage, infarct and direct injury to the brain tissue, all of which can cause neurological deficits. As explored elsewhere in this review, cerebral edema can be managed with corticosteroids, such as dexamethasone. Intracranial hemorrhage after surgery can be treated with expectant management versus surgical evacuation, based on the size and neurologic impact. Direct injury, mechanical injury and infarction from neurological surgery should be treated with rehabilitation [18] [19]. 


\section{Adverse Effects and Management of Radiation and Chemotherapies}

Three-dimensional conformal external beam radiation therapy (EBRT) is the standard method of radiation therapy delivery after surgical resection for GBM [20]. Radiation therapy is generally well tolerated, with most side effects seen in the pediatric population. Risks of radiation therapy include radiation dermatitis and alopecia [21], cognitive and endocrine dysfunctions, myelopathy, radionecrosis, vasculopathies, visual and hearing loss, the induction of secondary tumors including meningiomas, sarcomas and even gliomas [22]-[27]. For radiation induced dermatitis, over-the-counter emollient cream is used, or for more severe cases, topical steroids [28]. Cognitive dysfunction including learning issues and memory development is more pronounced when radiation treatment involves the hippocampus, providing rational for sparing the hip-pocampus when considering treatment planning for an increased quality of life [29]. Radiation therapy is well known to cause cerebral edema; however, in the authors' experience, corticosteroids are not commonly used unless symptomatic cerebral edema exists. In the case of symptomatic cerebral edema during radiation therapy, corticosteroid therapy, such as dexamethasone, is maintained and tapered down to the lowest permissible dose after completion.

Before temozolomide was introduced as a treatment, mainstream therapy for chemotherapy sensitive gliomas was PVC (procarbazine, lomustine and vincristine) therapy, which commonly induces myelosuppression, nausea and fatigue [30]. Studies have shown temozolomide as a more tolerable treatment with less myelosuppression and less frequent de-escalation of therapy [30], however many patients suffer from significant hematologic side effects and do not tolerate the entire six cycles of treatment. To mitigate these effects, a dose reduction of temozolomide can be attempted but is generally discontinued when less than $100 \mathrm{mg} / \mathrm{m}^{2} /$ day is required based on blood counts. Treatment of chemotherapy induced nausea has been described in detail elsewhere [31] and includes a variety of agents such as dexamethasone, $5-\mathrm{HT}_{3}$ antagonists such as granisetron, ondansetron and the dopamine $\mathrm{D}^{2}$ receptor antagonist metoclopramide. Treatments tailored based on patient response and clinician preference. Nausea treatment options are further explored in other sections of this review.

\section{Therapies under Investigation}

There are only a limited number of phase III clinical trials showing any benefit with medical therapies in glioblastoma patients (Table 1). However, there are numerous investigations in alternative therapies including gene, immune and targeted therapies [32]-[34]. Targeted therapies for glioblastoma have been challenging due to signal pathway redundancies [35]. One notable exception is targeting of BRAF V600E mutations, found in $50 \%$ of epithelioid glioblastomas, with the BRAF inhibitor vemurafenib showing a therapeutic response in children with the BRAF inhibitor vemurafenib, which has shown a therapeutic response in case reports with children with BRAFV600 Emutated tumors [36]-[37]. Investigations are premature, but have a promising future [32] [35]. 
Table 1. Phase III trials of chemotherapeutics showing benefit to glioblastoma patients.

\begin{tabular}{|c|c|c|}
\hline Treatment & Benefit & Reference \\
\hline $\begin{array}{l}\text { Radiotherapy plus concomitant and adjuvant } \\
\text { temozolomide for versus radiotherapy alone } \\
\text { for newly diagnosed glioblastoma }\end{array}$ & $\begin{array}{l}\text { Two-year survival rate was } 26.5 \\
\text { percent with radiotherapy plus } \\
\text { temozolomide and } 10.4 \text { percent } \\
\text { with radiotherapy only group }\end{array}$ & [7] \\
\hline $\begin{array}{l}\text { Addition of bevacizumab to radiotherapy and } \\
\text { temozolomide for newly diagnosed } \\
\text { glioblastoma }\end{array}$ & $\begin{array}{l}\text { Longer progression-free survival (10.6 } \\
\text { months vs. } 6.2 \text { months) with the } \\
\text { addition of bevacizumab }\end{array}$ & [73] \\
\hline $\begin{array}{l}\text { Bevacizumab and lomustine for } \\
\text { treating first recurrences }\end{array}$ & $\begin{array}{l}\text { Progression-free survival was } 4.17 \\
\text { months with combination } \\
\text { treatment vs. } 1.54 \text { months of those } \\
\text { receiving only lomustine }\end{array}$ & [74] \\
\hline $\begin{array}{l}\text { Cediranib as monotherapy, and in } \\
\text { combination with lomustine, versus } \\
\text { lomustine alone in patients with } \\
\text { recurrent glioblastoma }\end{array}$ & $\begin{array}{l}\text { Cediranib produced a modest } \\
\text { decreased time to deterioration } \\
\text { in neurologic status, } \\
\text { corticosteroid-sparing effects }\end{array}$ & [75] \\
\hline
\end{tabular}

Immune based therapies are an active area of interest and include investigations of peptide based vaccines, check point inhibitors, gene-based therapies and, recently, the development of chimeric antigen receptors. Investigations of targeted peptide and autologous tumor lysate therapies have shown promising results [38], but have not demonstrated efficacy in phase III trials to date. The peptide based vaccine rindopepimut epidermal growth factor receptor variant III (EGFRvIII), a mutation found in about one third of glioblastoma patients [39]. This did not demonstrate survival benefits with the follow-up phase III ACT IV trial in combination with standard therapy in EGFRvIII-positive glioblastoma [40]. Other promising glioma-as- sociated antigens currently investigated as targets include H3.3 K27M mutations glioblastomas [41] [42], heat-shock protein peptide complex-96 vaccine [43] and peptide based vaccines honing in on IDH mutant tumors [44]. Immune checkpoint inhibitors such as programed cell death-1 (PD-1) and programmed cell death ligand 1/PD-L1, as well as cytotoxic T-lymphocyte-associated molecule-4 (CTLA-4) have been shown in clinical trials to promote cancer regression [45] but there is currently no clinical data to support the use of these therapies for glioblastoma. There are, however, active recruitment for clinical trials underway, with supporting preclinical in vivo data [46]. These therapies come with their own set of side effects including mucositis, colitis, pneumonitis and others, which have been treated with corticosteroids [47].

There have been four gene therapy strategies investigated to treat gliomas, including oncolytic gene therapy, cytokine mediated gene therapy, tumor suppressor gene therapy and prodrug/suicide gene therapy [33]. A variety of vectors have been explored to deliver genes such as viruses, stem cells of neural, mesenchymal and embryonic origin, and synthetic nanoparticle vectors such as a cationic liposome [48]. Of these methods, viral vectors are the most commonly used since they are currently the most effective of 
all gene delivery methods [49].

Tumor suppressor gene therapy aims to correct carcinogenesis from tumor suppressor genes or their related pathways [50]. Preclinical data has supported targeting tumor suppressor genes p16 ${ }^{\mathrm{INK} 4 \mathrm{~A}}$, Phosphatase and Tensin Homologue (PTEN) and p53 [51] [52] [53] but no clinical trial has demonstrated benefit to date. Investigations are ongoing.

Cytokines play a crucial role in trafficking of the immune system [54]. As such, gene therapy targeting glioma cells has shown successful recruitment of immune cells leading to tumor destruction [33] [55]. A phase I study using 11 patients with stereotactic injection and using IFN- $\beta$-expressing replication-defective adenovirus showed histopathological evidence of tumor destruction. This has led to further ongoing studies [56]. Interestingly, a separate phase 1 study on five patients found $50 \%$ tumor reduction for 16 months or more in two patients with anaplastic astrocytoma [57]. In both cases, there was anaplastic astrocytoma after local administration of cationic liposomes containing the IFN- $\beta$ gene [57]. Synergistic combinational approaches with the cytokine and prodrug/suicide gene therapy have also been explored with some notable examples described below.

Prodrug/suicide gene therapy has been the most common gene therapy treatment for GBM [55]. This involves the introduction of a gene of viral or bacterial origin that manufactures compounds inducing induce cancer death, such as converting a prodrug into a lethal molecule [58]. Herpes simplex virus thymidine kinase (HSV-tk) converts the prodrug ganciclovir into deoxyguanosine triphosphate which leads to early chain termination of DNA strands, leading to cell death [59]. A phase III trial evaluated intratumor injection of retrovirus (RV)-mediated transduction of glioblastoma cells with (HSV- $t k$ ) gene, a type of suicide gene, followed by treatment with systemic ganciclovir plus standard therapy which failed to show benefit [60]. However, a similar study delivering the cytokine gene for interleukin 2 (IL-2) in addition to HSV-tk gene therapy for recurrent disease showed promise with tumor response in a small number of patients [61]. Based on promising preclinical data [62], combinational gene therapy interleukin 4 (IL-4) in addition to HSV- $t k$ is proposed for investigation in a phase I trial [63]. Toca 511 (vocimageneamiretrorepvec) is an investigational gene therapy using cytosine deaminase delivered as a retrovirus acting as a vector [64]. Cytosine Deaminase (CD) is an enzyme found in yeast and other microbes that converts the antifungal agent flucytosine (5-FC) into the antimetabolite agent 5-fluorouracil (5-FU), thereby killing tumor cells [65]-[67]. A phase 1 trial using Toca 511 on forty-five patients with recurrent or progressive high-grade glioma who underwent standard therapy were treated by means of multiple injections into the walls of the resection cavity. Subsequently Toca FC, a form of extended-release 5-fluorocytosine, was administered. A survival benefit was seen with the treatment group for a median overall survival of 13.6 months (95\% confidence interval, 10.8 to 20.0 ) compared to 7.1 months (95\% CI, 6.01 to 8.80 ) for the control arm which used lomustine for treatment. Notably, few related adverse events were found in the gene therapy arm, especially compared to the control 
arm (3.7\% versus $36.9 \%)$. Randomized phase II and III trials are currently underway [68].

Most oncolytic gene therapy employs replication-competent viral vectors that are designed to selectively replicate in target tumor cells and release viral particles to infect adjacent cancer cells, thereby resulting in destruction [33] [55]. Viruses that have been studied as oncolytic vectors for GBM include poliovirus, Newcastle disease virus, measles virus, reovirus, parvovirus, parvovirus and conditionally replicating adenovirus [33] [55] [69]. One notable example is G207, a conditionally replicating herpes simplex virus mutant vector that is a genetically engineered HSV-1 strain lacking the genes necessary for viral replication in normal cells. This strain is able to infect non-dividing cells with p16 inactivation or deletion, such as in the case of GBM [33] [70]. A phase 1 trial administering G207 stereotactically within GBMs 24 hours before surgical resection was studied in nine patients with recurrent malignant glioma who previously underwent standard therapy. Three of the nine patients had a radiographic response to the treatment with a median survival time of 7.5 months after the first treatment (95\% confidence interval: 3.0 - 12.7). This occurred at a median of 18 months after diagnosis of GBM (with a range of 11 - 51 months) [71]. One patient in the study was found to have an extended disease-free interval of 6 years [72]. A variety of other promising engineered oncolytic viruses are currently in early clinical trials.

\section{Maintaining Activities of Daily Living: Rehabilitation}

Previous studies have shown that rehabilitation of cancer patients improves physical functioning, fatigue, immune function, hemoglobin concentrations, potential markers of recurrence, body composition and overall quality of life [76]. Cancer rehabilitation should take into account the strong ties between social, psychological and physical components in life [77]. For the greatest preservation of function in glioma patients, occupational, physical and speech therapy should be pursued.

According to Dietz, cancer rehabilitation can be divided into four major components: preventive, restorative, supportive and palliative [78]. Preventive rehabilitation occurs when there is not yet loss of function, whether before or after treatment of cancer (including surgery, radiotherapy and/or chemotherapy). Restorative rehabilitation has the goal of maximizing the return of function in patients that have some level of impairment. Supportive rehabilitation prevents muscle wasting from inactivity and allows preservation of activities of daily living (ADL's) with the use of adaptive equipment and provides training to maintain as much independence as possible. Patients receiving care in this category are typically declining in function. The final category, palliative rehabilitation, maintains quality of life (QOL) while respecting the patient's wishes. This is done through relief of pain, dyspnea, edema, prevention of decubitus ulcers, prevention of contractures, positioning, breathing assistance and the use of assistive devices as warranted [77] [78].

The reality of facing a terminal illness combined with an altered body image after surgery often leads to depression in cancer patients [77]. This, as well as fatigue and 
other side effects that accompany chemo and radiation therapies, lead to decreased physical activity, followed by physiologic deconditioning [77] [79]. Should a patient's physical condition decline further, the focus of care should be on maintenance of activities of daily living and palliative care to maintain quality of life.

Patients should be encouraged to stay physically active through regular exercise. It has been shown that increased exercise behavior was found to be a strong independent predictor of survival in malignant glioma patients. In this study, patients that had greater than or equal to 9 metabolic equivalents (MET) hours per week had a median survival of 21.84 months versus 13.03 months for those with less than 9 MET hours per week [80]. To put this in perspective, strenuous exercise such as running and swimming would be 8 - 9 METs [80] [81]. Exercise is recommended at 5 days per week, 30 minutes per session at a brisk walk pace. There is increasing evidence that exercise modulates a variety of factors in the body including metabolism, sex-steroid hormone concentrations, immunological and angiogenic factors. This in turn may alter ligand availability in the tumor microenvironment [82]. Studies have shown that cancer patients who are informed and encouraged with telephone counseling, print-based material, step pedometers and oncologist-based advice increased their exercise behavior [80].

\section{Management of Cerebral Edema}

\subsection{Steroids}

Steroids play a key role in symptom management of brain tumor patients. Steroids are used for controlling tumor-associated edema [83]-[85], pain, nausea, vomiting and improving appetite [86]. In 1952, the French neurosurgeon Franc D. Ingraham pioneered the use of cortisone in postoperative neurosurgical patients [87]. In the1960's, French and Galicich were key in the investigation of the use of dexamethasone, which is currently the steroid of choice for today's brain tumors [88]. Compared to other steroids such as cortisone, dexamethasone was favorable for its lower index of sodium and water retention [89] [90], a long half life of 36 - 54 hours [91] and a decreased tendency to cause psychosis [90].

Steroids are often given 1 - 2 days prior to an elective surgical procedure to reduce cerebral edema and thereby improve clinical condition by the time of the craniotomy [89]. After surgery, patients are tapered to as low of a dose as possible. Unfortunately, there have been few prospective clinical trials to determine the optimal dose of dexamethasone in brain cancer patients [92] [93].

Glucocorticoids such as dexamethasone suppress inflammation and edema through a number of mechanisms. Most inflammatory factors are regulated by increased gene transcriptions controlled by factors including nuclear factor- $\kappa \mathrm{B}(\mathrm{NF}-\kappa \mathrm{B})$ and activator protein-1 (AP-1). Corticosteroids suppress inflammation by decreasing the expression of a wide range of cytokines, chemokines, adhesion molecules, inflammatory enzymes and receptors [94]. Glucocorticoids also have an immunosuppressive effect by promoting apoptosis of T lymphocytes [95]. 
It is well known that malignant brain tumors result in the breakdown of the blood brain barrier (BBB). The blood brain barrier is a highly regulated neurovascular unit comprised of endothelial cells, pericytes (at the capillary level), vascular smooth muscle cells (at the arterial level), astrocytes, microglia and neurons [96]. Astrocytes produce a variety of factors to maintain the integrity of the BBB [97]. The role of pericytes include regulation of $\mathrm{BBB}$ permeability, regulation of cerebral blood flow, clearance of toxic cellular byproducts and play a major role in stabilizing the microvasculature within the brain [96]. When a brain tumor occurs, the deficiency of normal astrocytes and pericyte coverage contribute to the breakdown. Moreover, brain tumors secrete vascular endothelial growth factor (VEGF) which increases the permeability of vasculature [98]. This breakdown of the $\mathrm{BBB}$ around brain tumors leads to the draining of fluid in the brain parenchyma within the extracelluar space, which occurs from openings in the interendothelial tight junctions, endothelial fenestrations and endothelial pincocytosis [99] [100]. Corticosteroids such as dexamethasone has been shown to reduce the permeability of this broken barrier [100] [101], partly through increased expression of components of tight junctions [102].

Despite the benefits, steroids are well known for their significant side effects. These include electrolyte disturbances, obesity, water retention, hirsutism, impaired wound healing, hypertension, immunosuppression, glucose intolerance, gastrointestinal bleeding, small bowel perforation, pancreatitis, increased appetite, cataracts, glaucoma, osteoporosis, neuropathy, myopathy, anxiety and psychosis, among others [103] [104]. Another issue with steroids is they may decrease the effectiveness of chemotherapy. Dexamethasone has been shown in vitro to inhibit apoptosis of glioblastoma cells treated with temozolomide through the induction of expression of the anti-apoptotic proteins $\mathrm{Bcl}-2$ and $\mathrm{Bcl}-\mathrm{xL}$ [105]. Steroids can also increase the metabolism of chemotherapy through the induction of the P450 system [106], thereby decreasing efficiency of treatment. The use of corticosteroids also requires prophylaxis from Pneumocystis pneu- monia [107] [108] and stomach ulcers, which will be touched upon later.

Given the side effects, it is important to taper steroids to the lowest possible dose. It is so important that there are studies suggesting increased survival with a successful steroid taper [109] [110]; steroid dependence in WHO grade III and IV tumors that were steroid-dependent had a relative death risk of 1.9 [110]. Unfortunately, there is limited data regarding a standardized approach. Patients with a Karnofsky performance scale of 90 - 100 were found more likely to have a successful taper and the most common cause of taper failure was headache [104]. In this study, steroid taper during radiotherapy (RT) was associated with steroid taper failure.

Tapering patients off of steroids requires close monitoring of symptoms. For a patient in good clinical condition, decreasing the steroid dose by $50 \%$ every 4 days can be adequate. During this process it is important to look for deterioration of the patient's condition. Should they perform poorly, returning to the prior dose and attempt tapering with a $25 \%$ decrease every 8 days is one common approach [111]. In the authors' clinical experience, it is recommend to dose patients twice daily with dexamethasone, 
and to take their first dose with breakfast and the second dose at lunch, rather than in the evening. By doing this, patients report better quality sleep and decreased night time urinary frequency.

Withdrawal from steroids is dependent on the dose used, the duration of treatment and the time taken to taper off of medication. Symptoms to look for include increased lethargy, low-grade fever, myalgias and arthalgias and signs of adrenal insufficiency, such as hypotension and skin pigmentation [112]. Signs of increased intracranial pressure (ICP) should also be watched for. These include papilledema, occipital headache worsening in the morning, nausea, vomiting, abnormal eye movement and impaired consciousness [111].

With all of these side effects, a careful approach is required while weighing the benefits and disadvantages of the dosage of steroids used. Like most medications, the frequency and severity of these side effects increased with dosages and treatment duration. It is recommended to use the lowest possible dose and to increase it when the patient becomes symptomatic from brain swelling.

\subsection{Bevacizumab}

Bevacizumab is a humanized monoclonal antibody that targets vascular endothelial growth factor A (VEGF-a). There have been two major recent trials, the Avastin in Glioblastoma (AVAglio) trial [73], based in the Europe, and the Radiation Therapy Oncology Group (RTOG) 0825 trial [113], based in United States. Both of these were randomized, double-blind, placebo-controlled trials. In both studies, the overall survival was not improved. Interestingly, quality of life was preserved and progression-free survival was prolonged in the AVAGlio trial, but not in RTOG-0825. The safety of bevacizumab was considered acceptable, but there was an increased risk of hypertension, thromboembolic events, intestinal perforation, and neutropenia [73] [113]. These results do not support the use of bevacizumab as the standard of care, however, it can be used to suppress intractable edema and thereby reduce mass effect in patients [114].

\subsection{Agents under Investigation}

Given the seemingly endless list of side effects associated with corticosteroid use, there have been investigations with other agents to reduce edema. Some of these agents currently being studied include cyclooxygenase-2 (COX-2) inhibitors [115] [116] and corticotrophin-releasing factor (CRF) [117] [118].

\section{Seizure Prevention}

Approximately $30 \%$ or more of brain tumor patients, including those with gliomas (all grades), have seizures at some point [106] [119]. Lower grade tumors tend to have a higher frequency of seizures [106]. Epileptic seizures are the presenting symptom in $30 \%-50 \%$ of all brain tumors [120]. Complications of treatment with prophylactic antiepileptic drugs (AEDs) include liver-dysfunction, dermatological symptoms, bonemarrow suppression and cognitive impairment [121] [122]. 
The basis for treatment of brain tumor patients with prophylactic antiepileptic drugs (AEDs) is grounded in the practice parameter released in 2000 by the American Academy of Neurology [121]. It states that patients with newly diagnosed brain tumors and no seizure history should not receive routine prophylactic AEDs, and that these patients should be tapered off medication after the first postoperative week. This decision was based on a meta-analysis showing a seizure risk reduction of at least $26 \%$, but with the frequent, sometimes serious side effects of medication. On average, around $24 \%$ of patients on AEDs had a severe enough reaction to quit treatment or switch medications. A limitation of this study is that it was conducted before leviracetam, the commonplace AED of choice, was available. By using AEDs within the first week after brain surgery, the incidences of seizures are reduced by $40 \%-50 \%$ [123]. This study also found no benefit with long term use.

When faced with a brain tumor patient with seizures, there are several options for medication (Table 2). Levetiracetam is currently the preferred AED for treating brain tumor patients since it is both effective and does not induce the P450 system [122]. It is a 2 nd generation anti-epileptic drug that has a unique mechanism of action where it binds to synaptic vesicle protein $2 \mathrm{~A}$ (SV2A) and acts as an inhibitor of synaptic vesicle

Table 2. Anticonvulsants.

\begin{tabular}{|c|c|c|c|}
\hline \multicolumn{4}{|c|}{ Anticonvulsants that Induce Hepatic Enzymes } \\
\hline Generic Name & Trade Name & Manufacturer & Reference \\
\hline Phenytoin & Dilantin & Pfizer & [211] \\
\hline Carbamazapine & Tegretol & Novartis & {$[212]$} \\
\hline Phenobarbital & Phenobarbital & Various & [213] \\
\hline Primidone & Mysoline & Various & [213] \\
\hline Oxcarbazapine & Trileptal & Novartis & {$[214]$} \\
\hline \multicolumn{4}{|c|}{ Anticonvulsants that Cause Modest or No Hepatic Induction } \\
\hline Generic Name & Trade Name & Manufacturer & Reference \\
\hline Valproic acid & Depakote & Abb Vie & [215] \\
\hline Gabapentin & Neurontin & Pfizer & [215] \\
\hline Felbamate & Felbatol & Mylan & [215] \\
\hline Lamotrigine & Lamictal & Glaxo Smith Kline & {$[215][216]$} \\
\hline Topiramate & Topamax & Janssen Pharmaceuticals & [215] \\
\hline Tiagabine & Gabtril & Teva Pharmaceuticals & [215] \\
\hline Levetiracetam & Keppra & UCB (Union chimiquebelge) & [216] \\
\hline Zonisamide & Zonagram & Concordia Pharmaceuticals & [217] \\
\hline Pregabalin & Lyrica & Pfizer & [218] \\
\hline Lacosamide & Vimpat & UCB (Union chimiquebelge) & [219] \\
\hline
\end{tabular}


exocytosis, thereby decreasing presynaptic neuro-transmitter release [124]. A prospective study over a 3 year period found that $91 \%$ of patients were seizure free with monotherapy of levetiracetam [106]. Leviracetam has been reported to cause irritability in some patients [125]-[127]. It has been observed at our institution that supplementation with $50 \mathrm{mg}$ of pyridoxine can help with this issue. Although preliminary, there has been data supporting supplementation with pyridoxine in children [128]. Of note, leviracetam has the added benefit of enhancing the effects of temozolomide [122] [129]. It has been shown to increase expression of histone deacetylase 1 (HDAC1) to ultimately silence methylguanine-DNA-methyltransferase (MGMT) [122].

Older AEDs such as phenytoin and carbamazepine unfavorably induce the P450 system [130] (Table 2). Phenytoin is especially more difficult to manage in conjunction with other medications. For example, co-administration with dexamethasone can increase or decrease levels of phenytoin. This means that careful monitoring is required to prevent seizures and to prevent phenytoin toxicity which can mimic tumor progression, namely with symptoms of nystagmus, ataxia and somnolence [131]. Additionally, phenytoin can induce liver enzymes such as the CYP3A4 system to cut in half the plasma half-life of dexamethasone and increase the clearance of cortisol [131]-[133]. It is therefore apparent that patients on both dexamethasone and phenytoin require careful monitoring, especially during tapering.

The U.S. Food and Drug Administration (FDA) delivered the statement in 2008 that AEDs may increase the risk of suicidal ideation [134]. The International League Against Epilepsy (ILAE) appointed a task force under the Commission on Neuropsychobiology to address and establish guidelines for the treatment of patients requiring AEDs with epilepsy psychiatric issues. In 2013, the Task Force found that the suicide risk with use is very low, and that stopping or refusing AEDs is significantly more dangerous and may result in death. It is also recommended that patients beginning to use or switching AEDs inform their physician of suicidal ideation or change in mood [135].

Although the parameter released by the American Academy of Neurology is at the time of this writing 16 years old, it remains the standard by which we manage AEDs are managed in brain tumor patients. This, and careful evaluation of patients during follow-up appointment, are the key to minimizing seizures.

\section{Gastrointestinal Considerations}

Glioma patients treated with corticosteroid are typically also treated prophylactically with $\mathrm{H} 2$ antagonists such as rantidine and famotidine [99]. Corticosteroids, especially when used in conjunction with nonsteroidal anti-inflammatory drugs (NSAIDs) [136], increase the risk of gastrointestinal complications such as gastritis or peptic ulcer disease [137]. $\mathrm{H}_{2}$ antagonists such rantidine and famotidine are used as prophylaxis against gastric ulcers. This is a rare event [138] with some studies suggesting no significant association with ulcer development and treatment with steroids [139] [140]. There have been no prospective studies showing that therapeutic doses of steroids cause ulcers. This is likely because of the low occurrence of this condition and difficulty in pa- 
tient recruitment. Anticoagulation therapy [141] along with a history of peptic ulcer disease is other factors that can increase the likelihood of gastrointestinal bleeding. Prophylactic therapy is probably unnecessary for most patients unless they are at a high risk for developing peptic ulceration (i.e., previous peptic ulcer disease, concurrent anticoagulation, NSAID therapy). When NSAIDs are necessary, use of a selective COX- 2 inhibitor may reduce the risk of gastrointestinal complications [142].

Antiemetics are required for glioblastoma patients on chemotherapy. Inadequately controlled emesis can negatively affect quality of life and compromise adherence to treatment [143] [144]. The major mechanism of chemotherapy-induced nausea is believed to originate at the small intestine [145]. Chemotherapy generates free radicals that induce enterochromaffin cells to release 5-hydroxytryptamine (5-HT) which then binds 5-hydroxytryptamine ${ }_{3}$ receptors to the wall of the intestine. This signal is relayed via vagal afferent fibers to the nucleus tractussolitarius and area postrema in the brain stem to produce the sensation of nausea and induce vomiting. Both of these areas within the central nervous system also contain $5-\mathrm{HT}_{3}$ receptors. Chemo therapy may also stimulate the area postrema directly since the blood brain barrier in this region is relatively permeable [145]. Antagonists of $5-\mathrm{HT}_{3}$ receptors such as ondansetron and metoclopramide are currently the most effective antiemetic class for chemotherapyinduced nausea and vomiting [145] and are useful for nausea prophylaxis in glioblastoma patients [7]. Synthetic cannabinoids such as nabilone and dronabinol have also been used successfully to treat nausea and vomiting from chemotherapy in cancer patients [146] [147] and may act as a useful adjunct for intractable nausea. Besides controlling brain tumor associated edema, steroids have been shown to help nausea both as a single agent [148] [149] and synergistically with 5- $\mathrm{HT}_{3}$ receptor antagonists [150] [151].

Since brain tumor patients are often treated with corticosteroids, they tend to experience appetite stimulation [152] and subsequent weight gain. If these patients require anti-epileptics, lamotrigine, topiramate and zonisamide can be considered as alternative for weight loss [153]. For patients who need to gain weight and appetite stimulation, phenytoin, valproic acid and carbamazepine [154] and synthetic cannabinoids [155] can be considered.

\section{Myopathy}

Glioma patients frequently suffer from decreased motility and fatigue. Combined with steroids, it becomes a difficult situation involving muscular atrophy from disuse, superimposed with steroid myopathy. Steroid myopathy affects up to $10 \%$ of primary brain tumor patients [156] [157]. This most commonly occurs the ninth and twelfth weeks of treatment [156].

Some strategies to combat this include sufficient protein intake [158] and exercise including physical therapy [159] [160], which have been used to preserve muscle composition and strength. There is also evidence that alternatively using glucocorticoids that fall within the nonfluorinated group, including hydrocortisone and prednisone, lead to less atrophy and greater retention of muscle strength [161] [162]. It would be a 
logical choice to try these steroids in a patient with myopathy needing long term steroids.

\section{Infection Prophylaxis}

Glioblastoma patients are at risk of infection due toimmunosuppression from chronic steroid use and therapy with temozolomide or other chemotherapies. Because of these treatments, glioblastoma patients require prophylaxis from fungal pneumonia caused by Pneumocystis jirovecii (previously known as Pneumocystis carinii) [7] [107] [108] [163]. Patients with the presentation of pneumonia should be investigated carefully, as Pneumocystis pneumonia is known to develop into an acute respiratory distress syndrome-like process (ARDS) like process [164].

From the authors' experience, one monthly dose of inhaled pentamidine is the preferred agent, as trimethoprim-sulfamethoxazole, although shown to be more effective, has a much higher frequency of adverse reactions. This is because it is absorbed systemically, while aerosolized pentamidine coats the inside of the lungs, and is hardly absorbed by the body [165] [166].

\section{Osteoporosis}

As discussed earlier, a GBM patient's physical activity is frequently hindered by reduced motility and fatigue. As a result, the bones in the body will follow Wolffs Law and develop decreased density from disuse [167]. Compounding this issue is corticosteroid use, which reduces bone density through several processes. Corticosteroid use leads to decreased sex hormones, calcium absorption and subsequent secondary hyperparathyroidism, decreased insulin-like growth factor-1 (IGF-1) and suppresses the ability of osteoblasts to synthesize boney matrix [168]. This is especially troubling since more than 90 percent of glioblastoma patients are advanced in age, with a mean age of 62 years [1]. As a preventive measure, bone mass can be maintained with physical therapy and exercise [167]. Supplementation with vitamin D, calcium, and bisphosphonates can also be utilized [169].

\section{Psychiatric/Psychological}

Glioblastoma patients have many overlapping issues that may affect their psychological wellbeing. Patients face a dismal reality of poor prognosis and infiltration of brain parenchyma by the cancer itself and neurological surgery can disrupt neuronal circuits vital to emotion [170]. Furthermore, increased intracranial pressure, radiation and chemotherapies have deleterious neuropsychiatric effects [171]-[173]. Chronic steroid use to control brain edema adds another layer of to the complexity with side effects commonly causing irritability, insomnia and anxiety [174].

\subsection{Neurocognitive Assessment}

Neurocognitive testing before and after treatment is important in the evaluation of glioblastoma patients. These evaluations typically address the ability of patients in top- 
ics such as information processing, psychomotor function, attention, verbal memory, working memory and executive function. With gliomas, this evaluation must take into account a myriad of influencing factors that affect the exam such treatment with neurosurgery, radiotherapy, chemotherapy, antiepileptics, steroids, as well as tumor-related epilepsy, age and psychological stress [175]. This battery of testing has been shown to predict survival in older populations of newly diagnosed patients [176]. Notably in one study, a decline in cognitive function predicted tumor recurrence nearly a month in advance of evidence in magnetic resonance imaging [177]. The information gained from neurological testing therefore is useful in directing rehabilitation therapy and in weighing the risks and benefits of treatments.

Compared to most other cancers, glioblastomas possess the unique challenge of affecting the brain, and therefore causes various cognitive deficits in areas such as executive function, memory and attention [178] [179]. In one study comparing patients with gliomas, patients with non-small cell lung cancer (NSCLC) and a healthy control group, glioma patients were more likely to have impaired social functioning. Impaired visual and motor functioning and seizures due to tumor burden also affect cognitive performance in glioma patients [179].

Cognitive therapy has been shown to benefit patients with glioblastomas [2]. In a randomized controlled trial, cognitive rehabilitation has been shown to have a salutary effect on short term cognitive complaints and on longer term cognitive performance and mental fatigue [178]. In another study, $60 \%$ of patients improved after therapy. Interestingly, younger patients and those with higher education were more likely to benefit. This finding was thought to reflect the brain reserve theory [180]. First described by Katzman et al. in 1988 in regard to Alzheimer patients [181], the brain reserve theory states that those who are younger and more educated may have a greater reserve of neurons which allows them to compensate for disease processes affecting the brain [182].

\subsection{Psychiatric Pharmaceutical Considerations}

A discrepancy between the rates of depression reported by physicians and patients was found in the Glioma Outcomes Project. In this study, 93\% of patients reported symptoms consistent with depression in the early postoperative period, while physicians reported depression in only $15 \%$ of patients. This discrepancy reflects the need for a new metric system when evaluating patients for depression. Brain tumor patients with depression have a reduced quality of life, higher mortality [183], increased cognitive impairment [184] and decreased overall survival [185]. In addition to seizure prophylaxis, AEDs are also use for pain control, appetite stimulation and a myriad of psychiatric disorders such as impulse control disorders, personality disorders and bipolar disorder [154]. As described earlier, a caveat is that many of them increase the metabolism of chemotherapy and corticosteroid treatment through induction of the P450 system (Table 2).

As previously discussed, majority of brain tumor patients appear to have depressive 
symptoms [173]. Unfortunately, the side effects of antidepressants, which include fatigue [186], cognitive impairment [187] and decreased seizures threshold [188], are innately found in brain tumor patients. We must tread carefully with the therapeutic options available. Serotonin reuptake inhibitors (SSRIs) and serotonin-norepinephrine reuptake inhibitors (SNRIs) have been used successfully with only modest side effects [99], and do not cause as much cognitive dysfunction as compared to tricyclic antidepressants (TCAs) [187]. It is important to keep in mind that the classic AEDs such as phenytoin, carbamazepine and valproic acid can increase the metabolism of antidepressant and therefore should be avoided if possible. AEDs that are not metabolized by the liver, such as levetiracetam (Table 2) are a better option for seizure prophylaxis [189].

Brain tumor patients also have an increased incidence of anxiety and impulsive behavioral changes [79] [154]. Options to help patients with impulsive behavior include carbamazepine, valproic acid, lamotrigine [190] and oxcarbazepine [191]. For issues with anxiety, the calcium channel modulating drug pregabalin was shown to be more effective than alprazolam for anxiety symptoms at one week of use [192]. Also, leviracetam has also been shown to have anxiolytic properties [193] [194]. The gammaaminobu-tyric acid (GABA) reuptake inhibitor tiagabine has been shown to decrease symptoms of anxiety and improved sleep with the same efficiency as paroxetine in a 10 week trial [195].

The combination of surgery, chemo and radiation therapy often leaves glioblastoma patients with chronic fatigue. In addition to encouraging physical activity [196] and cognitive therapy [178], there are pharmaceutical options to help patients. Methylphenidate has been shown to improve cognition, mood and function of brain tumor patients [197]. Unfortunately, the wakefulness promoting drug modafinil [198] was not shown to increase energy or decrease depressive symptoms in a recent double-blinded crossover trial in glioma patients [199]. Interestingly, an herb, American ginseng, has been recently shown in a double-blinded control study to help cancer patients with general fatigue with no significant side effects [200].

\section{Pain}

Up to $60 \%$ of all brain tumor patients report headaches [111]. This includes post-surgical headaches and a general chronic head discomfort. Instigating factors include meningeal irritation, radiation treatment and edema. Neuropathic pain can also occur with chemotherapy regimens [201] [202]. Carbamazepine, oxcarbazepine, valproic acid, lamotrigine, topmiramate, tiagabine, leviracetam, pregabalin and gabapentin have all been described for use in both migraine prophylaxis and neuropathic pain [203]. As discussed before, since brain tumor patients are often on chemotherapy and corticosteroids, it would be prudent to use medications that do not induce the liver (Table 2), such as leviracetam, pregabalin and gabapentin [154].

\section{Summarized Approach to Management}

Initially, glioblastoma patients should be discussed at a neuro-oncology tumor board 
for a multidisciplinary approach by physicians, including enrollment in clinical trials. At a minimum, a biopsy will be pursued to confirm the diagnosis. Removal of as much tumor as possible is performed at the discretion of the neurosurgeon, and an MRI of the brain is then obtained 48 to 72 hours after surgery. Tissue from the surgery is sent to a neuropathologist for histological evaluation and molecular analysis to guide treatment and prognostication.

Two to four weeks after surgery, unless contraindicated, most patients will begin standard therapy with the "Stupp protocol" [7] receiving external-beam radiation for 60 Gy in 30 fractions five days a week with concurrent temozolomide $75 \mathrm{mg} / \mathrm{m}^{2} /$ day orally on days 1 - 42. When this phase of treatment is completed, there is a 28-day break followed by an MRI to monitor response. The next phase of the protocol requires a larger dose of temozolomide at $150-200 \mathrm{mg} / \mathrm{m}^{2} /$ day orally on days $1-5$, every 28 days, for a total of six cycles. The first cycle is initiated at $150 \mathrm{mg} / \mathrm{m}^{2} /$ day and blood counts are drawn on days 21 and 28. If on both occasions the platelet count is greater than $100 \times$ $10^{9} / \mathrm{L}$ and the absolute neutrophil count is greater than $1.5 \times 10^{9} / \mathrm{L}$, cycles $2-6$ of temozolomide are given at an increased dose of $200 \mathrm{mg} / \mathrm{m}^{2}$ daily for five out of seven days per week. Further cycles require blood counts to be obtained just before the initiation of the subsequent cycle of chemotherapy. Additional blood counts are not obtained during cycles 2 - 6 unless the patient develops a fever of 100.5 degrees Fahrenheit or greater. An MRI will be obtained at cycles 3 and 5, and every two months thereafter through the first year after completion of chemotherapy. After the first year, the MRI interval can be increased to every three months, and then during the third year extended to every 4 months if there is no evidence of progression.

There is currently no official consensus on standard care for secondary treatments of GBM patients. When progression is found, patients are managed at the discretion of the treatment team. This may include a combination of additional surgery, radiotherapy and additional chemotherapies. It is reasonable to discuss clinical trials at this point.

From the authors' experience, bevacizumab can be used to decrease symptomatic mass effect from vasogenic edema (indicated by significant amounts of contrast enhancement on MRI imaging [204]) in cases where the tumor has progressed after second or third line treatments. Symptomatic mass effect can also be treated medically with the lowest possible dose of the corticosteroid dexamethasone to minimize the multitude of related side effects described earlier. Lymphocyte counts should be followed on a regular basis while receiving treatments and pneumocystis prophylaxis should be pursued with agents such as pentamidine or trimethoprim-sulfamethoxazole if the lymphocyte counts are found persistently low [165] [166].

A baseline neuropsychological evaluation should be performed as early as reasonably possible upon diagnosis of GBM for monitoring changes in cognition that could result from treatments or tumor burden. If seizure activity is suspected, an electroencephalogram can be considered for confirmation. For most GBM patients with seizures, levetiracetam is the preferred initial antiepileptic drug based on its excellent safety profile with minimal drug interactions [205]. Patients with seizures that are difficult to control 
should be referred to an epileptologist for further management and recommendations. Early in care, a referral is placed to a physician specializing in physical medicine and rehabilitation to address related deficits and maintain independence.

Throughout the course of this disease, patients as well as their family members undergo immense stress from declining health, loss of independence, as well as financial burden from job loss and medical costs. The psychological health of the patient and family should be screened at all clinic visits with resources including counseling, social work, support groups, respite care and psychiatric treatment offered on an as needed basis. Unfortunately the majority of GBM patients will have tumor progression despite treatment. The patient's personal wishes regarding hospice care and other concerns should be pursued with assistance of palliative care specialists. These topics should be explored as early as possible in the disease process, when the patient is more able to make difficult decisions.

\section{Conclusion}

Glioblastomas are among the most devastating of cancers, presenting with unique challenges affecting the quality of life of patients. The three most common causes of hospital admission for glioblastoma patients at the end of their life were, in decreasing order of frequency, immobility causing difficulty in home care, clinical deterioration and seizures [206]. Early palliative care and advanced-care planning can improve symptom control and quality of life for brain tumor patients [207]-[209]. In addition, early palliative care has been shown to improve the survival outcome of metastatic cancer patients by three months, attributed to improved symptom control, mood and overall quality of life [210]. These principles can be applied by close collaboration between members of the neuro-oncology team, with an emphasis of early symptom management as described by this review, including early integration of palliative care. With this approach, the optimization of the quality of life of glioblastoma patients can be achieved.

\section{Conflict of Interest}

The authors report no conflict of interest concerning the content of this paper.

\section{Acknowledgements}

We thank Rachael Swetnam for her assistance with editing the manuscript and Michael Parsons for his input in the neurocognitive section.

\section{References}

[1] Ohgaki, H. and Kleihues, P. (2009) Genetic Alterations and Signaling Pathways in the Evolution of Gliomas. Cancer Science, 100, 2235-2241. http://dx.doi.org/10.1111/j.1349-7006.2009.01308.x

[2] Vargo, M. (2011) Brain Tumor Rehabilitation. American Journal of Physical Medicine \& Rehabilitation, 90, S50-S62. http://dx.doi.org/10.1097/PHM.0b013e31820be31f

[3] Sanai, N. and Berger, M.S. (2008) Glioma Extent of Resection and Its Impact on Patient 
Outcome. Neurosurgery, 62, 753-764.

http://dx.doi.org/10.1227/01.neu.0000318159.21731.cf

[4] Ammirati, M., Vick, N., Liao, Y.L., et al. (1987) Effect of the Extent of Surgical Resection on Survival and Quality of Life in Patients with Supratentorial Glioblastomas and Anaplastic Astrocytomas. Neurosurgery, 21, 201-206. http://dx.doi.org/10.1227/00006123-198708000-00012

[5] Kelly, P.J., Daumas-Duport, C., Kispert, D.B., et al. (1987) Imaging-Based Stereotaxic Serial Biopsies in Untreated Intracranial Glial Neoplasms. Journal of Neurosurgery, 66, 865-874. http://dx.doi.org/10.3171/jns.1987.66.6.0865

[6] Dandy, W.E. (1928) Removal of Right Cerebral Hemisphere for Certain Tumors with Hemiplegia: Preliminary Report. The Journal of the American Medical Association, 90, 823. http://dx.doi.org/10.1001/jama.1928.02690380007003

[7] Stupp, R., Mason, W.P., van den Bent, M.J., et al. (2005) Radiotherapy plus Concomitant and Adjuvant Temozolomide for Glioblastoma. The New England Journal of Medicine, 352, 987-996. http://dx.doi.org/10.1056/NEJMoa043330

[8] Stupp, R., Tonn, J.-C., Brada, M., et al. (2010) High-Grade Malignant Glioma: ESMO Clinical Practice Guidelines for Diagnosis, Treatment and Follow-Up. Annals of Oncology, 21, v190-v193. http://dx.doi.org/10.1093/annonc/mdq187

[9] Herbert, C., Williams, M., Sawyer, H., et al. (2011) Treatment of Glioblastoma Multiforme with Radiotherapy and Concomitant and Adjuvant Temozolomide: Translation of Randomised Controlled Trial Evidence into Routine Clinical Practice. Journal of Clinical Oncology, 23, 372-373. http://dx.doi.org/10.1016/j.clon.2011.01.157

[10] Clarke, J., Butowski, N. and Chang, S. (2010) Recent Advances in Therapy for Glioblastoma. Archives of Neurology, 67, 279-283. http://dx.doi.org/10.1001/archneurol.2010.5

[11] Quick, A., Patel, D., Hadziahmetovic, M., et al. (2010) Current Therapeutic Paradigms in Glioblastoma. Reviews on Recent Clinical Trials, 5, 14-27. http://dx.doi.org/10.2174/157488710790820544

[12] Sherriff, J., Tamangani, J., Senthi,l L., et al. (2013) Patterns of Relapse in Glioblastoma Multiforme Following Concomitant Chemoradiotherapy with Temozolomide. The British Journal of Radiology, 86, Article ID: 20120414. http://dx.doi.org/10.1259/bjr.20120414

[13] Senft, C., Forster, M.-T., Bink, A., et al. (2012) Optimizing the Extent of Resection in Eloquently Located Gliomas by Combining Intraoperative MRI Guidance with Intraoperative Neurophysiological Monitoring. Journal of Neuro-Oncology, 109, 81-90. http://dx.doi.org/10.1007/s11060-012-0864-x

[14] Barnett, G.H. (1999) The Role of Image-Guided Technology in the Surgical Planning and Resection of Gliomas. Journal of Neuro-Oncology, 42, 247-258. http://dx.doi.org/10.1023/A:1006138609201

[15] Schulder, M. and Liang, D. (2012) The Role of Intraoperative Magnetic Resonance Imaging in Glioma Surgery. Surgical Neurology International, 3, 320. http://dx.doi.org/10.4103/2152-7806.103029

[16] Stummer, W., Pichlmeier, U., Meinel, T., et al. (2006) Fluorescence-Guided Surgery with 5-Aminolevulinic Acid for Resection of Malignant Glioma: A Randomised Controlled Multicentre Phase III Trial. The Lancet Oncology, 7, 392-401. http://dx.doi.org/10.1016/S1470-2045(06)70665-9

[17] Senft, C., Bink, A., Franz, K., et al. (2011) Intraoperative MRI Guidance and Extent of Resection in Glioma Surgery: A Randomised, Controlled Trial. The Lancet Oncology, 12, $997-$ 1003. http://dx.doi.org/10.1016/S1470-2045(11)70196-6 
[18] Dobkin, B.H. (2005) Rehabilitation after Stroke. The New England Journal of Medicine, 352, 1677-1684. http://dx.doi.org/10.1056/NEJMcp043511

[19] Kos, N., Kos, B. and Benedicic, M. (2016) Early Medical Rehabilitation after Neurosurgical Treatment of Malignant Brain Tumours in Slovenia. Radiology and Oncology, 50, 139-144.

[20] Walker, M.D., Alexander, E., Hunt, W.E., et al. (1978) Evaluation of BCNU and/or Radiotherapy in the Treatment of Anaplastic Gliomas. A Cooperative Clinical Trial. Journal of Neuro-Oncology, 49, 333-343. http://dx.doi.org/10.3171/jns.1978.49.3.0333

[21] Lawrence, Y.R., Wang, M., Dicker, A.P., et al. (2011) Early Toxicity Predicts Long-Term Survival in High-Grade Glioma. British Journal of Cancer, 104, 1365-1371. http://dx.doi.org/10.1038/bjc.2011.123

[22] Kondoh, T., Morishita, A., Kamei, M., et al. (2003) Moyamoya Syndrome after Prophylactic Cranial Irradiation for Acute Lymphocytic Leukemia. Pediatric Neurosurgery, 39, 264-269. http://dx.doi.org/10.1159/000072872

[23] Douw, L., Klein, M., Fagel, S.S., et al. (2009) Cognitive and Radiological Effects of Radiotherapy in Patients with Low-Grade Glioma: Long-Term Follow-Up. The Lancet Oncology, 8, 810-818. http://dx.doi.org/10.1016/S1474-4422(09)70204-2

[24] Crossen, J.R., Garwood, D., Glatstein, E. and Neuwelt, E.A. (1994) Neurobehavioral Sequelae of Cranial Irradiation in Adults: A Review of Radiation-Induced Encephalopathy. Journal of Clinical Oncology, 12, 627-642.

[25] Kortmann, R.-D., Timmermann, B., Taylor, R.E., et al. (2003) Current and Future Strategies in Radiotherapy of Childhood Low-Grade Glioma of the Brain: Part II: Treatment-Related Late Toxicity. Strahlentherapie und Onkologie, 179, 585-597. http://dx.doi.org/10.1007/s00066-003-8104-0

[26] Nandagopal, R., Laverdière, C., Mulrooney, D., et al. (2007) Endocrine Late Effects of Childhood Cancer Therapy: A Report from the Children's Oncology Group. Hormone Research in Paediatrics, 69, 65-74. http://dx.doi.org/10.1159/000111809

[27] Merchant, T.E., Kiehna, E.N., Li, C., et al. (2005) Radiation Dosimetry Predicts IQ after Conformal Radiation Therapy in Pediatric Patients with Localized Ependymoma. International Journal of Radiation Oncology • Biology • Physics, 63, 1546-1554. http://dx.doi.org/10.1016/j.ijrobp.2005.05.028

[28] Ulff, E., Maroti, M., Serup, J. and Falkmer, U. (2013) A Potent Steroid Cream Is Superior to Emollients in Reducing Acute Radiation Dermatitis in Breast Cancer Patients Treated with Adjuvant Radiotherapy. A Randomised Study of Betamethasone versus Two Moisturizing Creams. Radiotherapy \& Oncology, 108, 287-292. http://dx.doi.org/10.1016/j.radonc.2013.05.033

[29] Kazda, T., Jancalek, R., Pospisil, P., et al. (2014) Why and How to Spare the Hippocampus during Brain Radiotherapy: The Developing Role of Hippocampal Avoidance in Cranial Radiotherapy. Radiotherapy \& Oncology, 9, 139. http://dx.doi.org/10.1186/1748-717X-9-139

[30] van den Bent, M.J. (2003) Phase II Study of First-Line Chemotherapy with Temozolomide in Recurrent Oligodendroglial Tumors: The European Organization for Research and Treatment of Cancer Brain Tumor Group Study 26971. Journal of Clinical Oncology, 21, 2525-2528. http://dx.doi.org/10.1200/JCO.2003.12.015

[31] Jordan, K., Sippel, C. and Schmoll, H.-J. (2007) Guidelines for Antiemetic Treatment of Chemotherapy-Induced Nausea and Vomiting: Past, Present, and Future Recommendations. The Oncologist, 12, 1143-1150. http://dx.doi.org/10.1634/theoncologist.12-9-1143 
[32] Chen, R., Cohen, A.L. and Colman, H. (2016) Targeted Therapeutics in Patients with High-Grade Gliomas: Past, Present, and Future. Current Treatment Options in Oncology, 17, 42. http://dx.doi.org/10.1007/s11864-016-0418-0

[33] Okura, H., Smith, C.A. and Rutka, J.T. (2014) Gene Therapy for Malignant Glioma. Molecular and Cellular Therapies, 2, 21. http://dx.doi.org/10.1186/2052-8426-2-21

[34] Osoba, D., Brada, M, Prados, M.D. and Yung, W.A. (2000) Effect of Disease Burden on Health-Related Quality of Life in Patients with Malignant Gliomas. Journal of Neuro-Oncology, 2, 221-228. http://dx.doi.org/10.1215/15228517-2-4-221

[35] Wang, H., Xu, T., Jiang, Y., et al. (2015) The Challenges and the Promise of Molecular Targeted Therapy in Malignant Gliomas. Neoplasia, 17, 239-255.

http://dx.doi.org/10.1016/j.neo.2015.02.002

[36] Kleinschmidt-DeMasters, B.K., Aisner, D.L. and Foreman, N.K. (2015) BRAF VE1 Immunoreactivity Patterns in Epithelioid Glioblastomas Positive for BRAF V600E Mutation. The American Journal of Surgical Pathology, 39, 528-540. http://dx.doi.org/10.1097/PAS.0000000000000363

[37] Robinson, G.W., Orr, B.A. and Gajjar, A. (2014) Complete Clinical Regression of a BRAF V600E-Mutant Pediatric Glioblastoma Multiforme after BRAF Inhibitor Therapy. BMC Cancer, 14, 258.

[38] Prins, R.M., Wang, X., Soto, H., et al. (2013) Comparison of Glioma-Associated Antigen Peptide-Loaded Versus Autologous Tumor Lysate-Loaded Dendritic Cell Vaccination in Malignant Glioma Patients. Journal of Immunotherapy, 36, 152-157. http://dx.doi.org/10.1097/CJI.0b013e3182811ae4

[39] Heimberger, A.B., Hlatky, R., Suki, D., et al. (2005) Prognostic Effect of Epidermal Growth Factor Receptor and EGFRvIII in Glioblastoma Multiforme Patients. Clinical Cancer Research: American Association for Cancer Research, 11, 1462-1466. http://dx.doi.org/10.1158/1078-0432.CCR-04-1737

[40] Malkki, H. (2016) Trial Watch: Glioblastoma Vaccine Therapy Disappointment in Phase III trial. Nature Reviews Neurology, 12, 190-190. http://dx.doi.org/10.1038/nrneurol.2016.38

[41] Hou, Y., Kohanbash, G., Okada, K., et al. (2015) Novel and Shared Neoantigen for Glioma T Cell Therapy Derived from Histone 3 Variant H3.3 K27M Mutation. Journal for ImmunoTherapy of Cancer, 3, P445. http://dx.doi.org/10.1186/2051-1426-3-S2-P445

[42] Kohanbash, G., Okada, K., Liu, S., et al. (2016) Hg-81novel and Shared Neoantigen for Glioma T Cell Therapy Derived from Histone 3 Variant H3.3 K27m Mutation. Neuro-Oncology, 18, iii67.1-iii67.

[43] Bloch, O., Crane, C.A., Fuks, Y., et al. (2014) Heat-Shock Protein Peptide Complex-96 Vaccination for Recurrent Glioblastoma: A Phase II, Single-Arm Trial. Neuro-Oncology, 16, 274-279. http://dx.doi.org/10.1093/neuonc/not203

[44] Schumacher, T., Bunse, L., Pusch, S., et al. (2014) A Vaccine Targeting Mutant IDH1 Induces Antitumour Immunity. Nature, 512, 324-327. http://dx.doi.org/10.1038/nature13387

[45] Pardoll, D.M. (2012) The Blockade of Immune Checkpoints in Cancer Immunotherapy. Nature Reviews Cancer, 12, 252-264. http://dx.doi.org/10.1038/nrc3239

[46] Wainwright, D.A., Chang, A.L., Dey, M., et al. (2014) Durable Therapeutic Efficacy Utilizing Combinatorial Blockade against IDO, CTLA-4, and PD-L1 in Mice with Brain Tumors. Clinical Cancer Research, 20, 5290-5301. http://dx.doi.org/10.1158/1078-0432.CCR-14-0514

[47] Weber, J.S., Yang, J.C., Atkins, M.B. and Disis, M.L. (2015) Toxicities of Immunotherapy 
for the Practitioner. Journal of Clinical Oncology, 33, 2092-2099.

http://dx.doi.org/10.1200/JCO.2014.60.0379

[48] Ehtesham, M., Stevenson, C.B. and Thompson, R.C. (2005) Stem Cell Therapies for Malignant Glioma. Neurosurgical Focus, 19, E5. http://dx.doi.org/10.3171/foc.2005.19.3.6

[49] Felgner, P.L., Gadek, T.R., Holm, M., et al. (1987) Lipofection: A Highly Efficient, LipidMediated DNA-Transfection Procedure. Proceedings of the National Academy of Sciences of the United States of America, 84, 7413-7417. http://dx.doi.org/10.1073/pnas.84.21.7413

[50] Morris, L.G.T. and Chan, T.A. (2015) Therapeutic Targeting of Tumor Suppressor Genes: Therapeutic Targeting of Tumors. Cancer, 121, 1357-1368.

http://dx.doi.org/10.1002/cncr.29140

[51] Abe, T., Terada, K., Wakimoto, H., et al. (2003) PTEN Decreases in Vivo Vascularization of Experimental Gliomas in Spite of Proangiogenic Stimuli. Cancer Research, 63, 2300-2305.

[52] Chintala, S.K., Fueyo, J., Gomez-Manzano, C., et al. (1997) Adenovirus-Mediated p16/ CDKN2 Gene Transfer Suppresses Glioma Invasion in Vitro. Oncogene, 15, 2049-2057. http://dx.doi.org/10.1038/sj.onc.1201382

[53] Kim, S.-S., Rait, A., Kim, E., et al. (2015) A Tumor-Targeting p53 Nanodelivery System Limits Chemoresistance to Temozolomide Prolonging Survival in a Mouse Model of Glioblastoma Multiforme. Nanomedicine: Nanotechnology, Biology and Medicine, 11, 301-311. http://dx.doi.org/10.1016/j.nano.2014.09.005

[54] Lacy, P. and Stow, J.L. (2011) Cytokine Release from Innate Immune Cells: Association with Diverse Membrane Trafficking Pathways. Blood, 118, 9-18. http://dx.doi.org/10.1182/blood-2010-08-265892

[55] Tobias, A., Ahmed, A., Moon, K.-S. and Lesniak, M.S. (2013) The Art of Gene Therapy for Glioma: A Review of the Challenging Road to the Bedside. Journal of Neurology, Neurosurgery \& Psychiatry, 84, 213-222. http://dx.doi.org/10.1136/jnnp-2012-302946

[56] Chiocca, E.A., Smith, K.M., McKinney, B., et al. (2008) A Phase I Trial of Ad.hIFN- $\beta$ Gene Therapy for Glioma. Molecular Therapy, 16, 618-626. http://dx.doi.org/10.1038/sj.mt.6300396

[57] Yoshida, J., Mizuno, M., Fujii, M., et al. (2004) Human Gene Therapy for Malignant Gliomas (Glioblastoma Multiforme and Anaplastic Astrocytoma) by In Vivo Transduction with Human Interferon $\beta$ Gene Using Cationic Liposomes. Human Gene Therapy, 15, 77 86. http://dx.doi.org/10.1089/10430340460732472

[58] Duarte, S., Carle, G., Faneca, H., et al. (2012) Suicide Gene Therapy in Cancer: Where Do We Stand Now? Cancer Letters, 324, 160-170. http://dx.doi.org/10.1016/j.canlet.2012.05.023

[59] Beltinger, C., Fulda, S., Kammertoens, T., et al. (1999) Herpes Simplex Virus Thymidine Kinase/Ganciclovir-Induced Apoptosis Involves Ligand-Independent Death Receptor Aggregation and Activation of caspases. Proceedings of the National Academy of Sciences of the United States of America, 96, 8699-8704. http://dx.doi.org/10.1073/pnas.96.15.8699

[60] Rainov, N.G. (2000) A Phase III Clinical Evaluation of Herpes Simplex Virus Type 1 Thymidine Kinase and Ganciclovir Gene Therapy as an Adjuvant to Surgical Resection and Radiation in Adults with Previously Untreated Glioblastoma Multiforme. Human Gene Therapy, 11, 2389-2401. http://dx.doi.org/10.1089/104303400750038499

[61] Colombo, F., Barzon, L., Franchin, E., et al. (2005) Combined HSV-TK/IL-2 Gene Therapy in Patients with Recurrent Glioblastoma Multiforme: Biological and Clinical Results. Cancer Gene Therapy, 12, 835-848. http://dx.doi.org/10.1038/sj.cgt.7700851 
[62] Okada, H., Giezeman-Smits, K.M., Tahara, H., et al. (1999) Effective Cytokine Gene Therapy against an Intracranial Glioma Using a Retrovirally Transduced IL-4 plus HSVtk Tumor Vaccine. Gene Therapy, 6, 219-226. http://dx.doi.org/10.1038/sj.gt.3300798

[63] Okada, H., et al. (2000) Clinical Protocol: Gene Therapy of Malignant Gliomas: A Phase I Study of IL-4-HSV-TK Gene-Modified Autologous Tumor to Elicit an Immune Response. Human Gene Therapy, 11, 637-653. http://dx.doi.org/10.1089/10430340050015824

[64] Perez, O.D., Logg, C.R., Hiraoka, K., et al. (2012) Design and Selection of Toca 511 for Clinical Use: Modified Retroviral Replicating Vector with Improved Stability and Gene Expression. Molecular Therapy, 20, 1689-1698. http://dx.doi.org/10.1038/mt.2012.83

[65] Lv, S.-Q., Zhang, K.-B., Zhang, E.E., et al. (2009) Antitumor Efficiency of the Cytosine Deaminase/5-Fluorocytosine Suicide Gene Therapy System on Malignant Gliomas: An in Vivo Study. Medical Science Monitor. International Medical Journal of Experimental and Clinical Research, 15, BR13-BR20.

[66] Chen, J.K., Hu, L.J., Wang, D., et al. (2007) Cytosine Deaminase/5-Fluorocytosine Exposure Induces Bystander and Radiosensitization Effects in Hypoxic Glioblastoma Cells in Vitro. nternational Journal of Radiation Oncology • Biology • Physics, 67, 1538-1547. http://dx.doi.org/10.1016/j.ijrobp.2006.12.020

[67] Miller, C.R., Williams, C.R., Buchsbaum, D.J. and Gillespie, G.Y. (2002) Intratumoral 5-Fluorouracil Produced by Cytosine Deaminase/5-Fluorocytosine Gene Therapy Is Effective for Experimental Human Glioblastomas. Cancer Research, 62, 773-780.

[68] Cloughesy, T.F., Landolfi, J., Hogan, D.J., et al. (2016) Phase 1 Trial of Vocimagene Amiretrorepvec and 5-Fluorocytosine for Recurrent High-Grade Glioma. Science Translational Medicine, 8, 341ra75-341ra75.

[69] Kwiatkowska, A., Nandhu, M., Behera, P., et al. (2013) Strategies in Gene Therapy for Glioblastoma. Cancers, 5, 1271-1305. http://dx.doi.org/10.3390/cancers5041271

[70] Aghi, M., Visted, T., DePinho, R.A. and Chiocca, E.A. (2008) Oncolytic Herpes Virus with Defective ICP6 Specifically Replicates in Quiescent Cells with Homozygous Genetic Mutations in p16. Oncogene, 27, 4249-4254. http://dx.doi.org/10.1038/onc.2008.53

[71] Markert, J.M., Razdan, S.N., Kuo, H.-C., et al. (2014) A Phase I Trial of Oncolytic HSV-1, G207, Given in Combination with Radiation for Recurrent GBM demonstrates Safety and Radiographic Responses. Molecular Therapy, 22, 1048-1055.

[72] Whisenhunt, T.R., Rajneesh, K.F., Hackney, J.R. and Markert, J.M. (2015) Extended Disease-Free Interval of 6 Years in a Recurrent Glioblastoma Multiforme Patient Treated with G207 Oncolytic Viral Therapy. Oncolytic Virotherapy, 4, 33-38.

[73] Chinot, O.L., Wick, W., Mason, W., et al. (2014) Bevacizumab plus Radiotherapy-Temozolomide for Newly Diagnosed Glioblastoma. The New England Journal of Medicine, 370, 709-722. http://dx.doi.org/10.1056/NEJMoa1308345

[74] Wick, W., Brandes, A., Gorlia, T., et al. (2015) Lb-05phase Iii Trial Exploring the Combination of Bevacizumab and Lomustine in Patients with First Recurrence of a Glioblastoma: The Eortc 26101 Trial. Neuro-Oncology, 17, v1.5-v1.

[75] Batchelor, T.T., Mulholland, P., Neyns, B., et al. (2013) Phase III Randomized Trial Comparing the Efficacy of Cediranib as Monotherapy, and in Combination with Lomustine, versus Lomustine Alone in Patients with Recurrent Glioblastoma. Journal of Clinical Oncology, 31, 3212-3218. http://dx.doi.org/10.1200/JCO.2012.47.2464

[76] Spence, R.R., Heesch, K.C. and Brown, W.J. (2010) Exercise and Cancer Rehabilitation: A Systematic Review. Cancer Treatment Reviews, 36, 185-194.

http://dx.doi.org/10.1016/j.ctrv.2009.11.003 
[77] Okamura, H. (2011) Importance of Rehabilitation in Cancer Treatment and Palliative Medicine. Japanese Journal of Clinical Oncology, 41, 733-738.

http://dx.doi.org/10.1093/jjco/hyr061

[78] Dietz, J.H. (1969) Rehabilitation of the Cancer Patient. Medical Clinics of North America, 53, 607-624.

[79] Gillis, T.A., Yadav, R. and Guo, Y. (2002) Rehabilitation of Patients with Neurologic Tumors and Cancer-Related Central Nervous System Disabilities. 2nd Edition, Oxford University Press, New York, 341-361.

[80] Ruden, E., Reardon, D.A., Coan, A.D., et al. (2011) Exercise Behavior, Functional Capacity, and Survival in Adults with Malignant Recurrent Glioma. Journal of Clinical Oncology, 29, 2918-2923. http://dx.doi.org/10.1200/JCO.2011.34.9852

[81] Ainsworth, B.E., Haskell, W.L., Whitt, M.C., et al. (2000) Compendium of Physical Activities: an Update of Activity Codes and MET Intensities. Medicine \& Science in Sports \& EXercise, 32, S498-S504. http://dx.doi.org/10.1097/00005768-200009001-00009

[82] Thompson, H.J., Wolfe, P., McTiernan, A., et al. (2010) Wheel Running-Induced Changes in Plasma Biomarkers and Carcinogenic Response in the 1-Methyl-1-Nitrosourea-Induced Rat Model for Breast Cancer. Cancer Prevention Research, 3, 1484-1492. http://dx.doi.org/10.1158/1940-6207.CAPR-10-0078

[83] Miller, J.D. and Leech, P. (1975) Effects of Mannitol and Steroid Therapy on Intracranial Volume-Pressure Relationships in Patients. Journal of Neurosurgery, 42, 274-281. http://dx.doi.org/10.3171/jns.1975.42.3.0274

[84] Miller, J.D., Sakalas, R., Ward, J.D., et al. (1977) Methylprednisolone Treatment in Patients with Brain Tumors. Neurosurgery, 1, 114-117. http://dx.doi.org/10.1227/00006123-197709000-00005

[85] Yeung, W.T., Lee, T.Y., Del Maestro, R.F., et al. (1994) Effect of Steroids on Iopamidol Blood-Brain Transfer Constant and Plasma Volume in Brain Tumors Measured with X-Ray Computed Tomography. Journal of Neurosurgery, 18, 53-60. http://dx.doi.org/10.1007/BF01324604

[86] Markman, M., Sheidler, V., Ettinger, D.S., et al. (1984) Antiemetic Efficacy of Dexamethasone. The New England Journal of Medicine, 311, 549-552. http://dx.doi.org/10.1056/NEJM198408303110901

[87] Ingraham, F.D., Matson, D.D. and McLaurin, R.L. (1952) Cortisone and ACTH as an Adjunct to the Surgery of Craniopharyngiomas. The New England Journal of Medicine, 246, 568-571. http://dx.doi.org/10.1056/NEJM195204102461502

[88] French, L.A. and Galicich, J.H. (1964) The Use of Steroids for Control of Cerebral Edema. Clinical Neurosurgery, 10, 212-223.

[89] Bell, B.A., Smith, M.A., Kean, D.M., et al. (1987) Brain Water Measured by Magnetic Resonance Imaging. Correlation with Direct Estimation and Changes after Mannitol and Dexamethasone. Lancet, 1, 66-69. http://dx.doi.org/10.1016/S0140-6736(87)91908-8

[90] Ryken, T.C., McDermott, M., Robinson, P.D., et al. (2010) The Role of Steroids in the Management of Brain Metastases: A Systematic Review and Evidence-Based Clinical Practice Guideline. Journal of Neurosurgery, 96, 103-114. http://dx.doi.org/10.1007/s11060-009-0057-4

[91] Cross, K.P., Paul, R.I. and Goldman, R.D. (2011) Single-Dose Dexamethasone for Mild-toModerate Asthma Exacerbations Effective, Easy, and Acceptable. Canadian Family Physician, 57, 1134-1136. 
[92] Vecht, C.J., Hovestadt, A., Verbiest, H.B.C., et al. (1994) Dose-Effect Relationship of Dexamethasone on Karnofsky Performance in Metastatic Brain Tumors: A Randomized Study of Doses of 4, 8, and $16 \mathrm{mg}$ per Day. Neurology, 44, 675-675. http://dx.doi.org/10.1212/WNL.44.4.675

[93] Marantidou, A., Levy, C., Duquesne, A., et al. (2010) Steroid Requirements during Radiotherapy for Malignant Gliomas. Journal of Neurosurgery, 100, 89-94.

http://dx.doi.org/10.1007/s11060-010-0142-8

[94] Barnes, P.J. (2005) Molecular Mechanisms and Cellular Effects of Glucocorticosteroids. Immunology and Allergy Clinics of North America, 25, 451-468. http://dx.doi.org/10.1016/j.iac.2005.05.003

[95] Cifone, M.G., Migliorati, G., Parroni, R., et al. (1999) Dexamethasone-Induced Thymocyte Apoptosis: Apoptotic Signal Involves the Sequential Activation of Phosphoinositide-Specific Phospholipase C, Acidic Sphingomyelinase, and Caspases. Blood, 93, 2282-2296.

[96] Winkler, E.A., Bell, R.D. and Zlokovic, B.V. (2011) Central Nervous System Pericytes in Health and Disease. Nature Neuroscience, 14, 1398-1405.

http://dx.doi.org/10.1038/nn.2946

[97] Abbott, N.J., Rönnbäck, L. and Hansson, E. (2006) Astrocyte-Endothelial Interactions at the Blood-Brain Barrier. Nature Reviews Neuroscience, 7, 41-53. http://dx.doi.org/10.1038/nrn1824

[98] Machein, M.R. and Plate, K.H. (2000) VEGF in Brain Tumors. Journal of Neurosurgery, 50, 109-120. http://dx.doi.org/10.1023/A:1006416003964

[99] Wen, P., Schiff, D., Kesari, S., et al. (2006) Medical Management of Patients with Brain Tumors. Journal of Neurosurgery, 80, 313-332. http://dx.doi.org/10.1007/s11060-006-9193-2

[100] Papadopoulos, M.C., Saadoun, S., Binder, D.K., et al. (2004) Molecular Mechanisms of Brain Tumor Edema. Neuroscience, 129, 1011-1020. http://dx.doi.org/10.1016/j.neuroscience.2004.05.044

[101] Hedley-Whyte, E.T. and Hsu, D.W. (1986) Effect of Dexamethasone on Blood-Brain Barrier in the Normal Mouse. Annals of Neurology, 19, 373-377. http://dx.doi.org/10.1002/ana.410190411

[102] Förster, C., Silwedel, C., Golenhofen, N., et al. (2005) Occludin as Direct Target for Glucocorticoid-Induced Improvement of Blood-Brain Barrier Properties in a Murine in Vitro System. The Journal of Physiology, 565, 475-486. http://dx.doi.org/10.1113/jphysiol.2005.084038

[103] Koehler, P.J. (1995) Use of Corticosteroids in Neuro-Oncology. Anticancer Drugs, 6, 19-33. http://dx.doi.org/10.1097/00001813-199502000-00002

[104] Deutsch, M.B., Panageas, K.S., Lassman, A.B. and DeAngelis, L.M. (2013) Steroid Management in Newly Diagnosed Glioblastoma. Journal of Neurosurgery, 113, 111-116. http://dx.doi.org/10.1007/s11060-013-1096-4

[105] Das, A., Banik, N.L., Patel, S.J. and Ray, S.K. (2004) Dexamethasone Protected Human Glioblastoma U87MG Cells from Temozolomide Induced Apoptosis by Maintaining Bax: Bcl-2 Ratio and Preventing Proteolytic Activities. Molecular Cancer, 3, 36. http://dx.doi.org/10.1186/1476-4598-3-36

[106] Rosati, A., Buttolo, L., Stefini, R., et al. (2010) Efficacy and Safety of Levetiracetam in Patients with Glioma: A Clinical Prospective Study. Archives of Neurology, 2009, 335. http://dx.doi.org/10.1001/archneurol.2009.335 
[107] Sepkowitz, K.A., Brown, A.E., Telzak, E.E., et al. (1992) Pneumocystis Carinii Pneumonia among Patients without AIDS at a Cancer Hospital. JAMA, 267, 832-837.

http://dx.doi.org/10.1001/jama.1992.03480060078034

[108] Schiff, D. (1996) Pneumocystis Pneumonia in Brain Tumor Patients: Risk Factors and Clinical Features. Journal of Neurosurgery, 27, 235-240.

http://dx.doi.org/10.1007/BF00165480

[109] Gundersen, S., Lote, K. and Hannisdal, E. (1996) Prognostic Factors for Glioblastoma Multiforme-Development of a Prognostic Index. Acta Oncologica (Stockholm, Sweden), 35 123-127. http://dx.doi.org/10.3109/02841869609098530

[110] Watne, K., Hannisdal, E., Nome, O., et al. (1993) Prognostic Factors in Malignant Gliomas with Special Reference to Intra-Arterial Chemotherapy. Acta Oncologica (Stockholm, Sweden), 32, 307-310. http://dx.doi.org/10.3109/02841869309093600

[111] Kaal, E.C. and Vecht, C.J. (2004) The Management of Brain Edema in Brain Tumors. Current Opinion in Oncology, 16, 593-600. http://dx.doi.org/10.1097/01.cco.0000142076.52721.b3

[112] Amatruda, T.T., Hurst, M.M. and D’Esopo, N.D. (1965) Certain Endocrine and Metabolic Facets of the Steroid Withdrawal Syndrome. Journal of Clinical Endocrinology \& Metabolism, 25, 1207-1217. http://dx.doi.org/10.1210/jcem-25-9-1207

[113] Gilbert, M.R., Dignam, J.J., Armstrong, T.S., et al. (2014) A Randomized Trial of Bevacizumab for Newly Diagnosed Glioblastoma. The New England Journal of Medicine, 370, 699-708. http://dx.doi.org/10.1056/NEJMoa1308573

[114] Peak, S.J. and Levin, V.A. (2010) Role of Bevacizumab Therapy in the Management of Glioblastoma. Journal of Cancer Management and Research, 2, 97.

[115] Portnow, J., Suleman, S., Grossman, S.A., et al. (2002) A Cyclooxygenase-2 (COX-2) Inhibitor Compared with Dexamethasone in a Survival Study of Rats with Intracerebral 9L Gliosarcomas. Neuro-Oncoogylogy, 4, 22-25. http://dx.doi.org/10.1215/15228517-4-1-22

[116] Nathoo, N., Barnett, G.H. and Golubic, M. (2004) The Eicosanoid Cascade: Possible Role in Gliomas and Meningiomas. Journal of Clinical Pathology, 57, 6-13.

http://dx.doi.org/10.1136/jcp.57.1.6

[117] Tjuvajev, J., Uehara, H., Desai, R., et al. (1996) Corticotropin-Releasing Factor Decreases Vasogenic Brain Edema. Cancer Research, 56, 1352-1360.

[118] Villalona-Calero, M.A., Eckardt, J., Burris, H., et al. (1998) A Phase I Trial of Human Corticotropin-Releasing Factor (hCRF) in Patients with Peritumoral Brain Edema. Annals of Oncology, 9, 71-77. http://dx.doi.org/10.1023/A:1008251426425

[119] Hauser, W.A., Annegers, J.F. and Kurland, L.T. (1993) Incidence of Epilepsy and Unprovoked Seizures in Rochester, Minnesota: 1935-1984. Epilepsia, 34, 453-458. http://dx.doi.org/10.1111/j.1528-1157.1993.tb02586.x

[120] Herman, S.T. (2002) Epilepsy after Brain Insult: Targeting Epileptogenesis. Neurology, 59, S21-S26. http://dx.doi.org/10.1212/WNL.59.9_suppl_5.S21

[121] Glantz, M.J., Cole, B.F., Forsyth, P.A., et al. (2000) Practice Parameter: Anticonvulsant Prophylaxis in Patients with Newly Diagnosed Brain Tumors: Report of the Quality Standards Subcommittee of the American Academy of Neurology. Neurology, 54, 1886-1893. http://dx.doi.org/10.1212/WNL.54.10.1886

[122] Fonkem, E., Bricker, P., Mungall, D., et al. (2013) The Role of Levetiracetam in Treatment of Seizures in Brain Tumor Patients. Frontiers in Neurology, 4, 153.

http://dx.doi.org/10.3389/fneur.2013.00153 
[123] Temkin, N.R. (2002) Prophylactic Anticonvulsants after Neurosurgery. Epilepsy Currents, 2, 105-107. http://dx.doi.org/10.1046/j.1535-7597.2002.00038.x

[124] Yang, X.-F., Weisenfeld, A. and Rothman, S.M. (2007) Prolonged Exposure to Levetiracetam Reveals a Presynaptic Effect on Neurotransmission. Epilepsia, 48, 1861-1869. http://dx.doi.org/10.1111/j.1528-1167.2006.01132.x

[125] Cramer, J.A., De Rue, K., Devinsky, O., et al. (2003) A Systematic Review of the Behavioral Effects of Levetiracetam in Adults with Epilepsy, Cognitive Disorders, or an Anxiety Disorder during Clinical Trials. Epilepsy \& Behavior, 4, 124-132. http://dx.doi.org/10.1016/S1525-5050(03)00005-2

[126] Coppola, G., Mangano, S., Tortorella, G., et al. (2004) Levetiracetam during 1-Year FollowUp in Children, Adolescents, and Young Adults with Refractory Epilepsy. Epilepsy Research, 59, 35-42. http://dx.doi.org/10.1016/j.eplepsyres.2004.03.006

[127] Dinkelacker, V., Dietl, T., Widman, G., et al. (2003) Aggressive Behavior of Epilepsy Patients in the Course of Levetiracetam Add-On Therapy: Report of 33 Mild to Severe Cases. Epilepsy \& Behavior, 4, 537-547. http://dx.doi.org/10.1016/j.yebeh.2003.07.008

[128] Major, P., Greenberg, E., Khan, A. and Thiele, E.A. (2008) Pyridoxine Supplementation for the Treatment of Levetiracetam-Induced Behavior Side Effects in Children: Preliminary Results. Epilepsy \& Behavior, 13, 557-559. http://dx.doi.org/10.1016/j.yebeh.2008.07.004

[129] Bobustuc, G.C., Baker, C.H., Limaye, A., et al. (2010) Levetiracetam Enhances p53-mediated MGMT Inhibition and Sensitizes Glioblastoma Cells to Temozolomide. Neuro-Oncology, 12, 917-927. http://dx.doi.org/10.1093/neuonc/noq044

[130] Kuo, C.-C. (1998) A Common Anticonvulsant Binding Site for Phenytoin, Carbamazepine, and Lamotrigine in Neuronal Na+ Channels. Molecular Pharmacology, 54, 712-721.

[131] Ruegg, S. (2002) Dexamethasone/Phenytoin Interactions: Neurooncological Concerns. Swiss Medical Weekly, 132, 425-426.

[132] Chalk, J.B., Ridgeway, K., Brophy, T., et al. (1984) Phenytoin Impairs the Bioavailability of Dexamethasone in Neurological and Neurosurgical Patients. Journal of Neurology, Neurosurgery \& Psychiatry, 47, 1087-1090. http://dx.doi.org/10.1136/jnnp.47.10.1087

[133] Choi, Y., Thrasher, K., Werk, E.E., et al. (1971) Effect of Diphenylhydantoin on Cortisol Kinetics in Humans. Journal of Pharmacology and Experimental Therapeutics, 176, 27-34.

[134] Postmarket Drug Safety Information for Patients and Providers > Suicidal Behavior and Ideation and Antiepileptic Drugs. http://www.fda.gov/Drugs/DrugSafety/PostmarketDrugSafetyInformationforPatientsandPr oviders/UCM100190

[135] Mula, M., Kanner, A.M., Schmitz, B. and Schachter, S. (2013) Antiepileptic Drugs and Suicidality: An Expert Consensus Statement from the Task Force on Therapeutic Strategies of the ILAE Commission on Neuropsychobiology: Antiepileptic Drugs and Suicidality. Epilepsia, 54, 199-203. http://dx.doi.org/10.1111/j.1528-1167.2012.03688.x

[136] Wallace, J.L. (2000) How Do NSAIDs Cause Ulcer Disease? Baillières Best Practice \& Research Clinical Gastroenterology, 14, 147-159. http://dx.doi.org/10.1053/bega.1999.0065

[137] Weissman, D., Dufer, D., Vogel, V. and Abeloff, M. (1987) Corticosteroid Toxicity in Neuro-Oncology Patients. Journal of Neuro-Oncology, 5, 125-128. http://dx.doi.org/10.1007/BF02571300

[138] Conn, H.O. and Poynard, T. (1994) Corticosteroids and Peptic Ulcer: Meta-Analysis of Adverse Events during Steroid Therapy. Journal of Internal Medicine, 236, 619-632. http://dx.doi.org/10.1111/j.1365-2796.1994.tb00855.x

[139] Carson, J.L., Strom, B.L., Schinnar, R., et al. (1991) The Low Risk of Upper Gastrointestinal 
Bleeding in Patients Dispensed Corticosteroids. American Journal of Medicine, 91, 223228. http://dx.doi.org/10.1016/0002-9343(91)90119-I

[140] Conn, H.O. and Poynard, T. (1985) Adrenocorticosteroid Administration and Peptic Ulcer: A Critical Analysis. Journal of Chronic Diseases, 38, 457-468. http://dx.doi.org/10.1016/0021-9681(85)90028-1

[141] Barada, K., Abdul-Baki, H., El Hajj, II, et al. (2009) Gastrointestinal Bleeding in the Setting of Anticoagulation and Antiplatelet Therapy. Journal of Clinical Gastroenterology, 43, 5-12. http://dx.doi.org/10.1097/MCG.0b013e31811edd13

[142] Ballinger, A. and Smith, G. (2001) COX-2 Inhibitors vs. NSAIDs in Gastrointestinal Damage and Prevention. Expert Opinion on Pharmacotherapy, 2, 31-40. http://dx.doi.org/10.1517/14656566.2.1.31

[143] Lindley, C.M., Hirsch, J.D., O’Neill, C.V., et al. (1992) Quality of Life Consequences of Chemotherapy-Induced Emesis. Quality of Life Research, 1, 331-340. http://dx.doi.org/10.1007/BF00434947

[144] Bloechl-Daum, B. (2006) Delayed Nausea and Vomiting Continue to Reduce Patients' Quality of Life after Highly and Moderately Emetogenic Chemotherapy despite Antiemetic Treatment. Journal of Clinical Oncology, 24, 4472-4478. http://dx.doi.org/10.1200/JCO.2006.05.6382

[145] Hesketh, P.J. (2008) Chemotherapy-Induced Nausea and Vomiting. The New England Journal of Medicine, 358, 2482-2494. http://dx.doi.org/10.1056/NEJMra0706547

[146] Tramèr, M.R., Carroll, D., Campbell, F.A., et al. (2001) Cannabinoids for Control of Chemotherapy Induced Nausea and Vomiting: Quantitative Systematic Review. BMJ, 323, 16. http://dx.doi.org/10.1136/bmj.323.7303.16

[147] Sutton, I.R. and Daeninck, P. (2006) Cannabinoids in the Management of Intractable Chemotherapy-Induced Nausea and Vomiting and Cancer-Related Pain. The Journal of Supportive Oncology, 4, 531-535.

[148] Aapro, M.S. and Alberts, D.S. (1981) High-Dose Dexamethasone for Prevention of CisPlatin-Induced Vomiting. Cancer Chemotherapy and Pharmacology, 7, 11-14. http://dx.doi.org/10.1007/BF00258206

[149] Cassileth, P.A. (1983) Antiemetic Efficacy of Dexamethasone Therapy in Patients Receiving Cancer Chemotherapy. Archives of Internal Medicine, 143, 1347. http://dx.doi.org/10.1001/archinte.1983.00350070063012

[150] Hesketh, P.J., Harvey, W.H., Harker, W.G., et al. (1994) A Randomized, Double-Blind Comparison of Intravenous Ondansetron Alone and in Combination with Intravenous Dexamethasone in the Prevention of High-Dose Cisplatin-Induced Emesis. Journal of Clinical Oncology, 12, 596-600.

[151] Latreille, J., Stewart, D., Laberge, F., et al. (1995) Dexamethasone Improves the Efficacy of Granisetron in the First 24 h Following High-Dose Cisplatin Chemotherapy. Support Care Cancer, 3, 307-312.

[152] Loprinzi, C.L., Kugler, J.W., Sloan, J.A., et al. (1999) Randomized Comparison of Megestrol Acetate versus Dexamethasone versus Fluoxymesterone for the Treatment of Cancer Anorexia/Cachexia. Journal of Clinical Oncology, 17, 3299-3306.

[153] Ness-Abramof, R. and Apovian, C.M. (2005) Drug-Induced Weight Gain. Timely Top Med Cardiovasc Dis, 9, E31. http://dx.doi.org/10.1358/dot.2005.41.8.893630

[154] Thompson, D., Takeshita, J., Thompson, T. and Mulligan, M. (2006) Selecting Antiepileptic Drugs for Symptomatic Patients with Brain Tumors. The Journal of Supportive Oncology, 


\section{4, 411-416.}

[155] Berry, E.M. and Mechoulam, R. (2002) Tetrahydrocannabinol and Endocannabinoids in Feeding and Appetite. Pharmacology \& Therapeutics, 95, 185-190. http://dx.doi.org/10.1016/S0163-7258(02)00257-7

[156] Dropcho, E.J. and Soong, S.J. (1991) Steroid-Induced Weakness in Patients with Primary Brain tumors. Neurology, 41, 1235-1239. http://dx.doi.org/10.1212/WNL.41.8.1235

[157] Vick, N.A. (1988) Steroid Toxicity. Journal of Neuro-Oncology, 6, 199. http://dx.doi.org/10.1007/BF02327397

[158] Gupta, Y. and Gupta, A. (2013) Glucocorticoid-Induced Myopathy: Pathophysiology, Diagnosis, and Treatment. Indian Journal of Endocrinology and Metabolism, 17, 913. http://dx.doi.org/10.4103/2230-8210.117215

[159] La Pier, T.K. (1997) Glucocorticoid-Induced Muscle Atrophy. The Role of Exercise in Treatment and Prevention. Journal of Cardiopulmonary Rehabilitation and Prevention, 17, 76-84. http://dx.doi.org/10.1097/00008483-199703000-00002

[160] Braith, R.W., Welsch, M.A., Mills, R.M., et al. (1998) Resistance Exercise Prevents Glucocorticoid-Induced Myopathy in Heart Transplant Recipients. Medicine \& Science in Sports \& Exercise, 30, 483-489. http://dx.doi.org/10.1097/00005768-199804000-00003

[161] Kelly, F.J., McGrath, J.A., Goldspink, D.F. and Cullen, M.J. (1986) A Morphological/Biochemical Study on the Actions of Corticosteroids on Rat Skeletal Muscle. Muscle Nerve, 9, 1-10. http://dx.doi.org/10.1002/mus. 880090102

[162] Koski, C.L., Rifenberick, D.H. and Max, S.R. (1974) Oxidative Metabolism of Skeletal Muscle in Steroid Atrophy. Archives of Neurology, 31, 407-410. http://dx.doi.org/10.1001/archneur.1974.00490420073008

[163] Kovacs, J.A. and Masur, H. (2000) Prophylaxis against Opportunistic Infections in Patients with Human Immunodeficiency Virus Infection. The New England Journal of Medicine, 342, 1416-1429. http://dx.doi.org/10.1056/NEJM200005113421907

[164] Festic, E., Gajic, O., Limper, A.H. and Aksamit, T.R. (2005) Acute Respiratory Failure due to Pneumocystis Pneumonia in Patients without Human Immunodeficiency Virus Infection Outcome and Associated Features. Chest, 128, 573-579.

http://dx.doi.org/10.1378/chest.128.2.573

[165] Hardy, W.D., Feinberg, J., Finkelstein, D.M., et al. (1992) A Controlled Trial of Trimethoprim-Sulfamethoxazole or Aerosolized Pentamidine for Secondary Prophylaxis of Pneumocystis Carinii Pneumonia in Patients with the Acquired Immunodeficiency Syndrome. AIDS Clinical Trials Group Protocol 021. The New England Journal of Medicine, 327, 1842-1848. http://dx.doi.org/10.1056/NEJM199212243272604

[166] Schneider, M.M., Hoepelman, A.I., Eeftinck Schattenkerk, J.K., et al. (1992) A Controlled Trial of Aerosolized Pentamidine or Trimethoprim-Sulfamethoxazole as Primary Prophylaxis against Pneumocystis Carinii Pneumonia in Patients with Human Immunodeficiency Virus Infection. The Dutch AIDS Treatment Group. The New England Journal of Medicine, 327, 1836-1841. http://dx.doi.org/10.1056/NEJM199212243272603

[167] Woo SLK, S.C., Amiel, D., Gomez, M.A., Hayes, W.C., White, F.C. and Akeson, W.H. (1981) The Effect of Prolonged Physical Training on the Properties of Long Bone: A Study of Wolff s Law. Journal of Bone and Joint Surgery, 63, 780-787.

[168] Popp, A.W., Isenegger, J., Buergi, E.M., et al. (2006) Glucocorticosteroid-Induced Spinal Osteoporosis: Scientific Update on Pathophysiology and Treatment. European Spine Journal, 15, 1035-1049. http://dx.doi.org/10.1007/s00586-005-0056-x 
[169] Grossman, J.M., Gordon, R., Ranganath, V.K., et al. (2010) American College of Rheumatology 2010 Recommendations for the Prevention and Treatment of Glucocorticoid-Induced Osteoporosis. Arthritis Care \& Research, 62, 1515-1526.

http://dx.doi.org/10.1002/acr.20295

[170] Litofsky, N.S. and Resnick, A.G. (2009) The Relationships between Depression and Brain Tumors. Journal of Neuro-Oncology, 94, 153-161. http://dx.doi.org/10.1007/s11060-009-9825-4

[171] Weitzner, M.A. and Meyers, C.A. (1997) Cognitive Functioning and Quality of Life in Malignant Glioma Patients: A Review of the Literature. Psychooncology, 6, 169-177. http://dx.doi.org/10.1002/(SICI)1099-1611(199709)6:3<169::AID-PON269>3.0.CO;2-\#

[172] Crossen, J.R., Garwood, D., Glatstein, E. and Neuwelt, E.A. (1994) Neurobehavioral Sequelae of Cranial Irradiation in Adults: A Review of Radiation-Induced Encephalopathy. Journal of Clinical Oncology, 12, 627-642.

[173] Pelletier, G., Verhoef, M.J., Khatri, N. and Hagen, N. (2002) Quality of Life in Brain Tumor Patients: The Relative Contributions of Depression, Fatigue, Emotional Distress, and Existential Issues. Journal of Neuro-Oncology, 57, 41-49. http://dx.doi.org/10.1023/A:1015728825642

[174] Truhan, A.P. and Ahmed, A.R. (1989) Corticosteroids: A Review with Emphasis on Complications of Prolonged Systemic Therapy. Annals of Allergy, 62, 375-391.

[175] Bosma, I., Vos, M.J., Heimans, J.J., et al. (2007) The Course of Neurocognitive Functioning in High-Grade Glioma Patients. Journal of Neuro-Oncology, 9, 53-62. http://dx.doi.org/10.1215/15228517-2006-012

[176] Klein, M., Postma, T.J., Taphoorn, M.J.B., et al. (2003) The Prognostic Value of Cognitive Functioning in the Survival of Patients with High-Grade Glioma. Neurology, 61, 17961798. http://dx.doi.org/10.1212/01.WNL.0000098892.33018.4C

[177] Meyers, C.A., Hess, K.R., Yung, W.A. and Levin, V.A. (2000) Cognitive Function as a Predictor of Survival in Patients with Recurrent Malignant Glioma. Journal of Clinical Oncology, 18, 646.

[178] Gehring, K., Sitskoorn, M.M., Gundy, C.M., et al. (2009) Cognitive Rehabilitation in Patients with Gliomas: A Randomized, Controlled Trial. Journal of Clinical Oncology, 27, 3712-3722. http://dx.doi.org/10.1200/JCO.2008.20.5765

[179] Klein, M., Taphoorn, M.J., Heimans, J.J., et al. (2001) Neurobehavioral Status and HealthRelated Quality of Life in Newly Diagnosed High-Grade Glioma Patients. Journal of Clinical Oncology, 19, 4037-4047.

[180] Gehring, K., Aaronson, N.K., Gundy, C.M., et al. (2011) Predictors of Neuropsychological Improvement Following Cognitive Rehabilitation in Patients with Gliomas. Journal of the International Neuropsychological Society, 17, 256-266. http://dx.doi.org/10.1017/S1355617710001530

[181] Katzman, R., Terry, R., De Teresa, R., et al. (1988) Clinical, Pathological, and Neurochemical Changes in Dementia: A Subgroup with Preserved Mental Status and Numerous Neocortical Plaques. Annals of Neurology, 23, 138-144. http://dx.doi.org/10.1002/ana.410230206

[182] Stern, Y. (2002) What Is Cognitive Reserve? Theory and Research Application of the Reserve Concept. Journal of the International Neuropsychological Society, 8, 448-460. http://dx.doi.org/10.1017/S1355617702813248

[183] Mainio, A., Tuunanen, S., Hakko, H., et al. (2006) Decreased Quality of Life and Depression as Predictors for Shorter Survival among Patients with Low-Grade Gliomas: A Follow-Up 
from 1990 to 2003. European Archives of Psychiatry and Clinical Neuroscience, 256, 516521. http://dx.doi.org/10.1007/s00406-006-0674-2

[184] Armstrong, C., Goldstein, B., Cohen, B., et al. (2002) Clinical Predictors of Depression in Patients with Low-Grade Brain Tumors: Consideration of a Neurologic Versus a Psychogenic Model. J Journal of Clinical Psychology in Medical Settings, 9, 97-107.

http://dx.doi.org/10.1023/A:1014987925718

[185] Litofsky, N.S., Farace, E., Anderson, F., et al. (2004) Depression in Patients with HighGrade Glioma: Results of the Glioma Outcomes Project. Neurosurgery, 54, 358-367. http://dx.doi.org/10.1227/01.neu.0000103450.94724.a2

[186] Cassano, P. and Fava, M. (2004) Tolerability Issues during Long-Term Treatment with Antidepressants. Annals of Clinical Psychiatry, 16, 15-25. http://dx.doi.org/10.1080/10401230490281618

[187] Peretti, S., Judge, R. and Hindmarch, I. (2000) Safety and Tolerability Considerations: Tricyclic Antidepressants vs. Selective Serotonin Reuptake Inhibitors. Acta Psychiatrica Scandinavica, 403, 17-25. http://dx.doi.org/10.1111/j.1600-0447.2000.tb10944.x

[188] Montgomery, S.A. (2005) Antidepressants and Seizures: Emphasis on Newer Agents and Clinical Implications. International Journal of Clinical Practice, 59, 1435-1440. http://dx.doi.org/10.1111/j.1368-5031.2005.00731.x

[189] Hachad, H., Ragueneau-Majlessi, I. and Levy, R.H. (2002) New Antiepileptic Drugs: Review on Drug Interactions. Therapeutic Drug Monitoring, 24, 91-103. http://dx.doi.org/10.1097/00007691-200202000-00016

[190] Gajwani, P., Forsthoff, A., Muzina, D., et al. (2005) Antiepileptic Drugs in Mood-Disordered Patients. Epilepsia, 46, 38-44. http://dx.doi.org/10.1111/j.1528-1167.2005.463008.x

[191] Mattes, J.A. (2005) Oxcarbazepine in Patients with Impulsive Aggression: A Double-Blind, Placebo-Controlled Trial. Journal of Clinical Psychopharmacology, 25, 575-579. http://dx.doi.org/10.1097/01.jcp.0000186739.22395.6b

[192] Rickels, K., Pollack, M.H., Feltner, D.E., et al. (2005) Pregabalin for Treatment of Generalized Anxiety Disorder: A 4-Week, Multicenter, Double-Blind, Placebo-Controlled Trial of Pregabalin and Alprazolam. Archives of General Psychiatry, 62, 1022-1030. http://dx.doi.org/10.1001/archpsyc.62.9.1022

[193] Simon, N.M., Worthington, J.J., Doyle, A.C., et al. (2004) An Open-Label Study of Levetiracetam for the Treatment of Social Anxiety Disorder. Journal of Clinical Psychiatry, 65, 1219-1222. http://dx.doi.org/10.4088/JCP.v65n0909

[194] Kinrys, G., Worthington, J.J., Wygant, L., et al. (2007) Levetiracetam as Adjunctive Therapy for Refractory Anxiety Disorders. Journal of Clinical Psychiatry, 68, 1010-1013. http://dx.doi.org/10.4088/JCP.v68n0705

[195] Rosenthal, M. (2003) Tiagabine for the Treatment of Generalized Anxiety Disorder: A Randomized, Open-Label, Clinical Trial with Paroxetine as a Positive Control. Journal of Clinical Psychiatry, 64, 1245-1249. http://dx.doi.org/10.4088/JCP.v64n1016

[196] Dimeo, F.C., Stieglitz, R.-D., Novelli-Fischer, U., et al. (1999) Effects of Physical Activity on the Fatigue and Psychologic Status of Cancer Patients during Chemotherapy. Cancer, 85, 2273-2277.

http://dx.doi.org/10.1002/(SICI)1097-0142(19990515)85:10<2273::AID-CNCR24>3.0.CO;2$\underline{\mathrm{B}}$

[197] Meyers, C.A., Weitzner, M.A., Valentine, A.D. and Levin, V.A. (1998) Methylphenidate Therapy Improves Cognition, Mood, and Function of Brain Tumor Patients. Journal of Clinical Oncology, 16, 2522-2527. 
[198] Erman, M.K. and Rosenberg, R., Modafinil Shift Work Sleep Disorder Study Group (2007) Modafinil for Excessive Sleepiness Associated with Chronic Shift Work Sleep Disorder: Effects on Patient Functioning and Health-Related Quality of Life. The Primary Care Companion: Journal of Clinical Psychiatry, 9, 188-194. http://dx.doi.org/10.4088/PCC.v09n0304

[199] Boele, F.W., Douw, L., de Groot, M., et al. (2013) The Effect of Modafinil on Fatigue, Cognitive Functioning, and Mood in Primary Brain Tumor Patients: A Multicenter Randomized Controlled Trial. Journal of Neuro-Oncology, 15, 1420-1428.

http://dx.doi.org/10.1093/neuonc/not102

[200] Barton, D.L., Liu, H., Dakhil, S.R., et al. (2013) Wisconsin Ginseng (Panax quinquefolius) to Improve Cancer-Related Fatigue: A Randomized, Double-Blind Trial, N07C2. Journal of the National Cancer Institute, 105, 1230-1238. http://dx.doi.org/10.1093/jnci/djt181

[201] Gutiérrez-Gutiérrez, G., Sereno, M., Miralles, A., et al. (2010) Chemotherapy-Induced Peripheral Neuropathy: Clinical Features, Diagnosis, Prevention and Treatment Strategies. Clinical and Translational Oncology, 12, 81-91. http://dx.doi.org/10.1007/S12094-010-0474-z

[202] Quasthoff, S. and Hartung, H.P. (2002) Chemotherapy-Induced Peripheral Neuropathy. Journal of Neurology, 249, 9-17. http://dx.doi.org/10.1007/PL00007853

[203] Rogawski, M.A. (2006) Molecular Targets versus Models for New Antiepileptic Drug Discovery. Epilepsy Research, 68, 22-28. http://dx.doi.org/10.1016/j.eplepsyres.2005.09.012

[204] Cha, S. (2006) Update on Brain Tumor Imaging: From Anatomy to Physiology. American Journal of Neuroradiology, 27, 475-487.

[205] Patsalos, P.N. (2004) Clinical Pharmacokinetics of Levetiracetam. Clinical Pharmacokinetics, 43, 707-724. http://dx.doi.org/10.2165/00003088-200443110-00002

[206] Oberndorfer, S., Lindeck-Pozza, E., Lahrmann, H., et al. (2008) The End-of-Life Hospital Setting in Patients with Glioblastoma. Journal of Palliative Medicine, 11, 26-30. http://dx.doi.org/10.1089/jpm.2007.0137

[207] Lin, E., Rosenthal, M.A., Le, B.H. and Eastman, P. (2012) Neuro-Oncology and Palliative Care: A Challenging Interface. Journal of Neuro-Oncology, 14, iv3-iv7. http://dx.doi.org/10.1093/neuonc/nos209

[208] Walbert, T. (2014) Integration of Palliative Care into the Neuro-Oncology Practice: Patterns in the United States. Neuro-Oncology Practice, 1, 3-7. http://dx.doi.org/10.1093/nop/npt004

[209] Temel, J.S., Greer, J.A., Muzikansky, A., et al. (2010) Early Palliative Care for Patients with Metastatic Non-Small-Cell Lung Cancer. The New England Journal of Medicine, 363, 733742. http://dx.doi.org/10.1056/NEJMoa1000678

[210] Palmer, J.L. and Fisch, M.J. (2005) Association between Symptom Distress and Survival in Outpatients Seen in a Palliative Care Cancer Center. Journal of Pain and Symptom Management, 29, 565-571. http://dx.doi.org/10.1016/j.jpainsymman.2004.11.007

[211] Fleishaker, J.C., Pearson, L.K. and Peters, G.R. (1995) Phenytoin Causes a Rapid Increase in 6 Beta-Hydroxycortisol Urinary Excretion in Humans: A Putative Measure of CYP3A Induction. Journal of Pharmaceutical Sciences, 84, 292-294. http://dx.doi.org/10.1002/jps.2600840305

[212] Isojärvi, J.I.T. (1990) Serum Steroid Hormones and Pituitary Function in Female Epileptic Patients during Carbamazepine Therapy. Epilepsia, 31, 438-445. http://dx.doi.org/10.1111/j.1528-1157.1990.tb05500.x

[213] Brodie, M.J., Mintzer, S., Pack, A.M., et al. (2013) Enzyme Induction with Antiepileptic Drugs: Cause for Concern? Enzyme Induction with AEDs. Epilepsia, 54, 11-27. 
http://dx.doi.org/10.1111/j.1528-1167.2012.03671.x

[214] Isojärvi, J.I., Pakarinen, A.J., Rautio, A., et al. (1994) Liver Enzyme Induction and Serum Lipid Levels after Replacement of Carbamazepine with Oxcarbazepine. Epilepsia, 35, 12171220. http://dx.doi.org/10.1111/j.1528-1157.1994.tb01792.x

[215] Anderson, G.D. (1998) A Mechanistic Approach to Antiepileptic Drug Interactions. Annals of Pharmacotherapy, 32, 554-563. http://dx.doi.org/10.1345/aph.17332

[216] Abou-Khalil, B.W. (2009) The Far-Reaching Influence of Hepatic Enzyme-Inducing Antiepileptic Drugs. Epilepsy Currents, 9, 158-159. http://dx.doi.org/10.1111/j.1535-7511.2009.01327.x

[217] Leppik, I.E. (2004) Zonisamide: Chemistry, Mechanism of Action, and Pharmacokinetics. Seizure, 13, S10. http://dx.doi.org/10.1016/j.seizure.2004.04.016

[218] Fuzier, R., Serres, I., et al., The French Network of Pharmacovigilance Centres (2013) Adverse Drug Reactions to Gabapentin and Pregabalin: A Review of the French Pharmacovigilance Database. Drug Safety, 36, 55-62. http://dx.doi.org/10.1007/s40264-012-0006-6

[219] Tolman, J. and Faulkner, M. (2011) Treatment Options for Refractory and Difficult to Treat Seizures: Focus on Vigabatrin. Journal of Therapeutics and Clinical Risk Management, 7, 367-375. http://dx.doi.org/10.2147/TCRM.S8519

Submit or recommend next manuscript to SCIRP and we will provide best service for you:

Accepting pre-submission inquiries through Email, Facebook, LinkedIn, Twitter, etc. A wide selection of journals (inclusive of 9 subjects, more than 200 journals)

Providing 24-hour high-quality service

User-friendly online submission system

Fair and swift peer-review system

Efficient typesetting and proofreading procedure

Display of the result of downloads and visits, as well as the number of cited articles Maximum dissemination of your research work

Submit your manuscript at: http://papersubmission.scirp.org/

Or contact jct@scirp.org 